WFPS: TME-79-016

MARCH 1979

UC-20, 20d

\title{
RESONANCE SELF-SHIELDING IN THE BLANKET OF A HYBRID REACTOR
}

\author{
ISRAEL NIR \\ CARNEGIE-MELLON UNIVERSITY
}

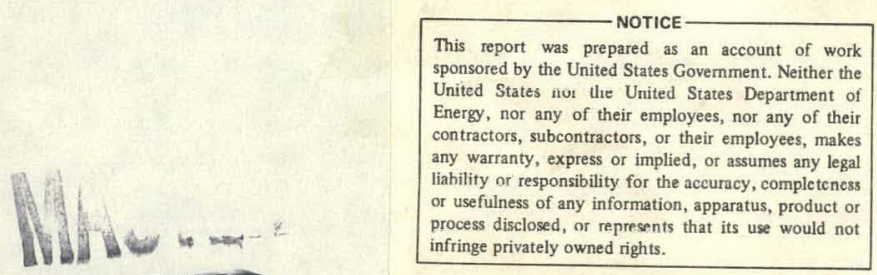

COOPERATIVE GRADUATE EDUCATION PROGRAM IN FUSION TECHNOLOGY ADMINISTERED FOR THE U.S. DEPARTMENT OF ENERGY

BY THE WESTINGHOLSE ELECTRIC CORPORATION

CONTRACT EG-77-C-02-4231-A000 


\section{DISCLAIMER}

This report was prepared as an account of work sponsored by an agency of the United States Government. Neither the United States Government nor any agency Thereof, nor any of their employees, makes any warranty, express or implied, or assumes any legal liability or responsibility for the accuracy, completeness, or usefulness of any information, apparatus, product, or process disclosed, or represents that its use would not infringe privately owned rights. Reference herein to any specific commercial product, process, or service by trade name, trademark, manufacturer, or otherwise does not necessarily constitute or imply its endorsement, recommendation, or favoring by the United States Government or any agency thereof. The views and opinions of authors expressed herein do not necessarily state or reflect those of the United States Government or any agency thereof. 


\section{DISCLAIMER}

Portions of this document may be illegible in electronic image products. Images are produced from the best available original document. 
WFPS:TME-79-016

MARCH 1979

\section{RESONANCE SELF-SHIELDING IN THE BLANKET OF A HYBRID REACTOR}

PREPARED BY: $\frac{\text { Cswael Hei }}{\begin{array}{l}\text { Israel Nir } \\ \text { Nuclear Engineering Department } \\ \text { Carnegie-Mellon University }\end{array}}$

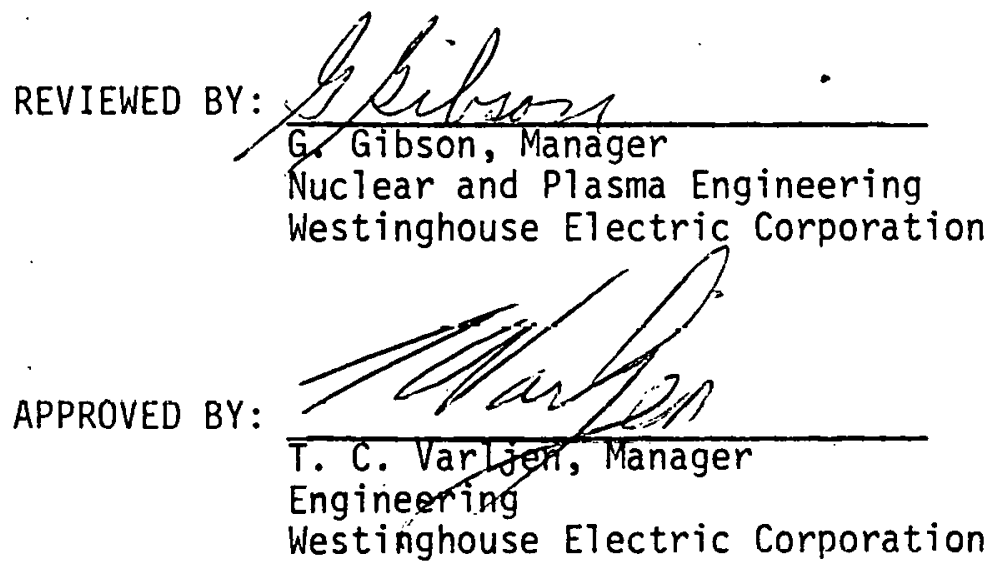

fusion pourer systems deportment

(WV) Westinghouse Electric Corporation P.O. Bon 10864, Pgn. Po. 15236

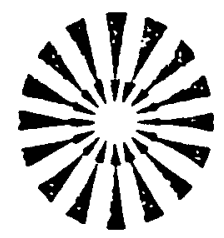


ACKNOWLEDGEMENT

This work was performed for the U.S. Department of Energy, under Contract EG-77-C-02-4237-A000, Cooperative Graduate Education Program in Fusion Technology. Reproduction, translation, publication, use and disposal, in whole or in part, by or for the United States Government is permitted.

The author is indebted to many people for the contributions that made this work possible. Special thanks go to my advisors, D. Chapin and Y. A. Chao, and to G. Gibson. I would like to express my gratitude to all those people that made my participation in this program possible, and in particular to Dr. D. Klein for his continuous support.

\section{LEGAL NOTICE}

This report was prepared as an account of Government sponsored work. Neither the United States, nor the Administration, nor any person acting on behalf of the Administration:

A. Makes any warranty or representation, expressed or implied, with respect to the accuracy, completeness, or usefulness of the information contained in this report, or that the use of any information, apparatus, method or process disclosed in this report may not infringe privately owned rights; or

B. Assumes any liabilities with respect to the use of, or for damages resulting from the use of any information, apparatus, method, or process disclosed in this report.

Printed in the United States of America Available from

National Technical Information Service

U.S. Department of Commerce

5285 Port Royal Road

Springfield VA 22161

Price: Printed Copy $\$ 4.50$; Microfiche $\$ 3.00$ 


\section{ABSTRACT}

Three sets of energy group cross sections were obtained using various approximations for resonance self shielding. The three models used in obtaining the cross sections were: a) infinitely dilute model, b) homogeneous-medium resonance self shielding, and c) heterogeneous-medium resonance self shielding. The effects on the blanket performance of fusion-fission hybrid reactors, and in particular, on the performance of the current reference Westinghouse Demonstration Tokamak Hybrid Reactor blanket, were compared and analysed for a variety of fuel-coolant combinations. It has been concluded that 1) the infinitely dilute cross sections can be used to produce preliminary crude estimates for beginningof-life (BOL) only, 2) the resonance absorber finite dilution should be considered for BOL, poorly moderated blankets and well moderated blankets with low fissile material content situations, and 3 ) the spacial details should be considered in high fissile content, well moderated blanket situations. 
Section No.

1.0

INTRODUCTION

2.0 SYSTEM SETUP

3.0 GROUP CONSTANTS EVALUATION MODELS

3.1 INFINITELY DILUTE MODEL

3.2 HOMOGENEOUS MEDIUM SELF-SHIELDING MODEL

3.3 HETEROGENEOUS MEDIUM SELF-SHIELDING MODEL

4.0

BOL FUEL BLANKET

4.1 INFINITELY DILUTE MODEL

4.1.1 Th/U-233 CYCLE

4.1.2 U/PU-239 CYCLE

4.2 HOMOGENEOUS MEDIUM SELF-SHIELDING MODEL

4.2.1 Th/U-233 CYCLE

4.2.2 U/PU-239 CYCLE

4.3 HEI LROGENEOUS MEDIUM SELF-SHIELDING MODEL

4.3.1 Th/U-233 CYCLE

4.3.2 U/PU-239 CYCLE

4.4 DISCUSSION

4.4.1 Th/II-2.3.3 C.YC.I.E

4.4.2 U/PU-239 CYCLE

5.0 ENRICHED FUEL BLANKET

6.0 SUMMARY AND CONCLUSIONS

$7.0^{\circ}$ REFERENCES
Page ilo.

$1-1$

2-1

3-1

$3-1$

$3-1$

$3-2$

$4-1$

4-5

4-5

4-7

4-10

4-10

4-12

4-10

4-18

4-21

4-21

4-21

4-24

5-1

6-1

7-1 
Figure No.

Page No.

4-1 U-233 Production Rate, Per $\mathrm{cm}^{3}$, Per Neutron from Plasma, for Various Coolants, Using Infinitely Cilute Model

U-238 Fission Rate, Per $\mathrm{cm}^{3}$, Per Neutron from Plasma in $\mathrm{H}_{2} \mathrm{O}$ and He Cooled Blankets, Using Infinitely Dilute Model

4-3 U-235 Fission Rate, Per $\mathrm{cm}^{3}$, Per Neutron from Plasma for Various Coolants, Using Infinitely Dilute Model

4-4 Pu-239 Production Rate, Per $\mathrm{cm}^{3}$, Per Neutron from Plasma, for Various Coolants, Using Infinitely Dilute Model

4-5 U-233 Production Rate, Per $\mathrm{cm}^{3}$, Per Neutron from Plasma for Various Coolants, Using Homogeneous Medium SelfShielding Model

4-6 Comparison of U-233 Production Rate, Per $\mathrm{cm}^{3}$, Per Neutron from Plasma, Between Homogeneous Medium Self-Shielded and Infinitely Dilute Treated Blankets, Cooled by $\mathrm{He}$ and $\mathrm{H}_{2} \mathrm{O}$

4-7 U-235 Fission Rate, Per $\mathrm{cm}^{3}$, Per Neutron from Plasma, for Various Coolants, Using Homogeneous Medium Self-Shielding Model

4-8 Comparison of U-235 Fission Rate, Per $\mathrm{cm}^{3}$, Per Neutron from Plasma Between Homogeneous Medium Self-Shielded and Infinitely Dilute Treated Blankets, Cooled by $\mathrm{He}$ and $\mathrm{H}_{2} \mathrm{O}$

4-9 Comparison of U-238 Fission Rate, Per $\mathrm{cm}^{3}$, Per Neutron from Plasma, Between Homogeneous Medium Self-Shielded and Infinitely Dilute Treated Blankets, Cooled by He and $\mathrm{H}_{2} \mathrm{O}$

4-10 Pu-239 Production Rate, Per $\mathrm{cm}^{3}$, Per Neutron from Plasma, for Various Coolants, Using Homogeneous Medium SelfShielding Model

4-11 Comparison of Pu-239 Production Rate, Per $\mathrm{cm}^{3}$, Per Neutron from Plasma, Between Homogeneous Medium Self-Shielded and Infinitely Dilute Treated Blankets, Cooled by $\mathrm{He}$ and $\mathrm{H}_{2} \mathrm{O}$

4-12 Comparison of U-235 Fission Rate, Per $\mathrm{cm}^{3}$, Per Neutron from Plasma, Between Homogeneous and Heterogeneous Medium Self-Shielded Blanket.s 
Figure No.

Page No. .

5-1 Multiplication Factor, in the U/Pu-239 Cycle, Versus U-235 Fraction in Uranium, for Various Self-Shielding Treatments

5-2 Net Fissile Material Production, in the U/Pu-239 Cycle, Versus U-235 Fraction in Uranium, for Various SelfShielding Treatments 


\section{LIST OF TABLES}

Table No.

Page No.

2-1 SYSTEM SETUP

$2-2$

2-2 DESCRIPTION OF MATERIALS USED IN NEUTRONIC CALCULATIONS

$2-3$

2-3 $\mathrm{UO}_{2}$ COMPONENTS NUMBER DENSITIES AS FUNCTION OF U-235 CONCENTRATION IN URANIUM

2-4 BLANKET FUEL LATTICE.

2-5 ENERGY GROUPS DEVISION

$2-6$

4-1 Th/U-233 CYCLE: BLANKET PERFORMANCE AND NEUTRON BALANCE, PER NEUTRON EMITTED FROM PLASMA, FOR VARIOUS MODERATORS AND SELF-SHIELDING TREATMENTS

4-2 U/PU-239 CYCLE: BLANKET PERFORMANCE AND NEUTRON BALANCE, PER NEUTRON EMITTED FROM PLASMA, FOR VARIOUS MODERATORS AND SELF-SHIELDING TREATMENTS $(0.25 \%$ U-235 TAILS)

4-3 RESONANCE INTEGRAL VALUES FOR Th-232 AND U-238 $(n, \gamma)$

REACTIONS FOR VARIOUS SELF-SHIELDING TREATMENTS

4-4 INTEGRATED Th-232 AND U-238 ( $n, \gamma)$ REACTION OVER THE RESONANCE AND NON-RESONANCE ENERGY RANGES, PER NEUTRON EMITTED FROM PLASMA

5-1 U/PU-239 CYCLE: BLANKET PERFORMANCE AND NEUTRON BALANCE, PER NEUTRON EMITTED FROM PLASMA, FOR VARIOUS SELF-SHIELDING TRFATMFNTS AND U-235 FRACTIONS ( $\mathrm{H}_{2} \mathrm{O}$ MODERATION) 


\subsection{INTRODUCTION}

The development of a fusion-fission hybrid reactor device depends, in part, on the neutronic calculations capability to describe correctly the underlying neutronic processes, especially within the blanket zone. This capability, in turn, depends on the manner in which energy group nuclear cross sections are evaluated. It is the goal of this paper to determine the effects of the different energy group constants evaluation models on the blanket performance of fusionfission hybrid reactors, and in particular, on the performance of the current reference DTHR blanket.

The neutronic calculations were performed using the one dimensional, discrete ordinate computer code ANISN, ${ }^{2}$ using an $\mathrm{S}_{8}$ angular quadrature treatment and $\mathrm{P}_{3}$ anisotropic scattering approximation. Group cross sections were generated with a computer processing package that uses the BONAMI subroutine for resonance treatment utilizing the ORNL-RSIC distributed CTR processed library. ${ }^{3}$

Three group constants evaluation models were used:

1. Infinitely d17ute group constanls

2. Homogeneous medium resonance self-shielding

3. Heterogeneous medium resonance self-shielding

The resonance self-shielding effects were isolated by using a reference hybrid geometry with fixed material compositions for the different resonance selfshielding treatments. However, a wide range of fuel-coolant compositions were used in order to enable performance analyses of different hybrid blankets candidates. Both Th/U-233 and U/Pu-239 fuel cycles were treated, using water, steam and He as coolants for each fuel choice. The various group constants obtained for the various model-fuel-coolant combinations were analyzed and compared on the basis of neutron balance, blanket performance and various detailed reaction rates within the blanket. Only $\mathrm{BOL}$ fuel was used for this set of calculations. Utilizing the results of the calculations described, another set of calculations was performed, using the previous basic setup with $\mathrm{UO}_{2}$-water blanket composition, 
where the U-235 content in the Uranium was varied. Neutron balance and blanket performance analyses for this set of calculations are presented. 


\subsection{SYSTEM SETUP}

The system setup used in the neutronic calculations follows the basic design of the DTHR ${ }^{1}$ (Demonstration Tokamak Hybrid Reactor). The main zones considered are the plasma, first wall, fissile breeding blanket, reflector and shield. Table 2-1 presents the different zones, their radial boundaries, the different components and their volume fraction in each zone. The general geometry setup assumes cylindrical symmetry using the poloidal plasma axis as axis of symmetry. While this symmetry is far from perfect (e.g. the inner core of the hybrid is completely neglected), it was recognized that:

a) The resonance self-shielding effects depend mainly on the resonance self-shielding treatments and are not sensitive to small changes in the geometry.

b) It is relatively simple.

Table 2-2 gives a detailed description of the different materials used throughout the calculations, including material density, components and number density for each component. Three remarks are in order:

a) The water density is $1 \mathrm{gm} / \mathrm{cm}^{3}$ wherever water is used (either as a coolant or as a reflector).

b) He was treated as a void in the calculations due to its low density and small cross section.

c) The $U 0_{2}$ contains $0.25 \%$ U-235 tails.

The above information was used for the first set of calculations.

In the second set of calculations only $\mathrm{UO}_{2}$ fuel and water coolant were used where the U-235 content in the Uranium was varied. The description given in Tables 2-1 and 2-2 is applicable for this case as well. In addition Table 2-3 displays the different U-235 fraction and the various number densities used. 


\section{TABLE 2-1}

\section{SYSTEM SETLP}

\begin{tabular}{|l|c|c|c|}
\hline \multicolumn{1}{|c|}{ ZONE } & $\begin{array}{c}\text { RADIAL } \\
\text { BOUNDARIES (cM) }\end{array}$ & $\begin{array}{c}\text { COMPONENTS } \\
\text { IN ZONE }\end{array}$ & $\begin{array}{c}\text { COMPONENT VOLUME } \\
\text { FRACTION IN ZONE }\end{array}$ \\
\hline \multirow{2}{*}{ PLASMA } & $0-120$ & PLASMA & 1.00 \\
VOID & $120-140$ & VOID & 1.00 \\
FIRST WALL & $140-141$ & SS-316 & 0.50 \\
VOID & VOID & 0.50 \\
BLANKET & $141-150$ & FUEL & 1.00 \\
& $150-185$ & COOLANT & 0.57 \\
& & ZR & 0.24 \\
& & VOID & 0.17 \\
RFFLECTOR & $185-200$ & SS-316 & 0.02 \\
& & H2 & 0.35 \\
SHIELD & \multirow{2}{*}{$200-250$} & SS-316 & 0.65 \\
& & BORATED WATER & 0.35 \\
& & & \\
\hline
\end{tabular}


TABLF. 2-2

DESCRIPTION OF MATERIALS LISED IN! THE NEUTRONIC CALCULATIONS

\begin{tabular}{|c|c|c|c|c|}
\hline $\begin{array}{l}\text { MATERIAL } \\
\text { TYPE }\end{array}$ & MATERIAL & $\begin{array}{l}\text { DENSITY } \\
\left(\mathrm{GM} / \mathrm{CM}^{3}\right)\end{array}$ & $\begin{array}{l}\text { MATERIAL } \\
\text { COMPONENTS }\end{array}$ & $\begin{array}{c}\text { NUMBER DENSITY } \\
\left(10^{-2} \text {. ATOM/BARN-CM }\right)\end{array}$ \\
\hline \multirow[t]{2}{*}{ FUEL } & $\mathrm{THO}_{2}$ & 9.65 & $\begin{array}{c}\text { TH-232 } \\
0-16\end{array}$ & $\begin{array}{l}2.201 \\
2.201 \\
4.402\end{array}$ \\
\hline & $\mathrm{LO}_{2}$ & 10.40 & $\begin{array}{l}U-235 \\
U-238 \\
0-16\end{array}$ & $\begin{array}{l}2.319 \\
5.797 \cdot 10^{-3} \\
2.313 \\
4.638\end{array}$ \\
\hline \multirow[t]{2}{*}{ COOLANT } & $\mathrm{H}_{2} \mathrm{O}$ & 1.00 & $\begin{array}{l}H \\
0-16 .\end{array}$ & $\begin{array}{l}3.344 \\
6.688 \\
3.344\end{array}$ \\
\hline & STFAMI & 0.0641 & $\begin{array}{l}H \\
0-1 E\end{array}$ & $\begin{array}{l}0.214 \\
0.428 \\
0.214\end{array}$ \\
\hline \multirow[t]{2}{*}{ STRUCTURE } & $S S-316$ & 7.97 & $\begin{array}{l}\text { FE } \\
C_{R} \\
N_{I} \\
M_{N} \\
M O\end{array}$ & $\begin{array}{l}8.570 \\
5.720 \\
1.570 \\
0.981 \\
0.174 \\
0.125\end{array}$ \\
\hline & $Z R$ & 6.49 & & 4.284 \\
\hline SHIELD & $\begin{array}{l}\text { BORATED } \\
\mathrm{H}_{2} \mathrm{O}\end{array}$ & 1.00 & $\begin{array}{l}H \\
0-16 \\
B-10 \\
B-11\end{array}$ & $\begin{array}{l}6.688 \\
3.344 \\
9.639 \cdot 10^{-3} \\
3.954 \cdot 10^{-2}\end{array}$ \\
\hline
\end{tabular}


TABLE 2-3

$\mathrm{UO}_{2}$ COMPONENTS NUMBER DENSITIES

AS FUNCTION OF U-235 CONCENTRATION IN URANIUM

\begin{tabular}{|c|c|c|c|}
\hline \multirow{2}{*}{$\begin{array}{c}\text { U-235 CONCENTRATION } \\
\text { IN URANIUM (\%) }\end{array}$} & \multicolumn{3}{|c|}{ NUMPER DENSITY (atom/barn-cm) } \\
\cline { 2 - 4 } & $U-235$ & $U-238$ & $0-16$ \\
\hline 0.25 & $5.797 \cdot 10^{-5}$ & $2.313 \cdot 10^{-2}$ & $4.638 \cdot 10^{-2}$ \\
1.00 & $2.319 \cdot 10^{-4}$ & $2.296 \cdot 10^{-2}$ & $4.638 \cdot 10^{-2}$ \\
1.75 & $4.058 \cdot 10^{-4}$ & $2.278 \cdot 10^{-2}$ & $4.638 \cdot 10^{-2}$ \\
2.50 & $5.797 \cdot 10^{-4}$ & $2.261 \cdot 10^{-2}$ & $4.638 \cdot 10^{-2}$ \\
\hline
\end{tabular}

For the calculation within the heterogeneous medium self-shielding model, which takes into account the spacial details of the blanket fuel lattice, a single lattice structure had been used. The blanket consists of an hexagonal lattice of fuel rods. The lattice geometry details are described in Table 2-4.

TABLE 2-4

BLANKET FUEL LATTICE

$\begin{array}{ll}\text { FUEL RADIUS } & 0.65 \mathrm{~cm} \\ \text { FUEL-CLAD GAP } & 0.008 \mathrm{~cm} \\ \text { CLAD WIDTH } & 0.065 \mathrm{~cm} \\ \text { LATTICE PITCH } & 1.64 \mathrm{~cm} \\ \text { EFFECTTVE UNIT CELL RADIUS } & 0.86 \mathrm{~cm} \\ \text { AVERAGE TEMPERATURE } & 666^{\circ} \mathrm{K} \\ \text { FUEL TEMPERATURE } & 900^{\circ} \mathrm{K} \\ \text { COOLANT TEMPERATURE } & 550^{\circ} \mathrm{K}\end{array}$

The effective unit cell radius was obtained by keeping the fuel volume to total volume ratio fixed, which leads to the simple relation:

$$
\text { (1attice pitch) }=\sqrt{\frac{2 \pi}{\sqrt{3}}} \times \text { (effective unit cell radius) }
$$


The effective unit cell radius is needed for the spacial resonance self-shielding effects calculations. The average temperature was used in the homogeneous medium calculations while the fuel and moderator temperatures were used in the heterogeneous calculations.

The neutronic calculations were performed using the one dimensional, discrete ordinate computer code $A N I S N^{2}$, using an $S_{8}$ angular quadrature treatment and $P_{3}$ anisotropic scattering approximation.

The multi-group cross section library used in the calculations was the 171 neutron group CTR processed 7 ibrary ${ }^{3}$ distributed by ORNL-RSIC. It was produced from ENDF/B-IV by the ORNL AMPX code system. Included with the library is a set of Bondarenko factors ${ }^{4}$ which are used to perform the resonance self-shielding. Also included with the cross section library is a set of codes to retrieve, edit, collapse, and self-shield the cross-sections. The code that performs the resonance self-shielding calculations is called BONAMI.

To calculate the cross sections for use in this study, the selff-shielding was first performed in the entire 171 group library using one of the approximations discussed below. Then, the library was collapsed to the 27 group structure shown in Table 2,-5 using a spectrum with a high energy $D-T$ fusion peak connected to a fission spectrum connected to a "l/E" slowing down spectrum connected to a thermal Maxwellian distribution. 
TABLE 2-5

ENERGY GROUPS DEVISION

\section{GROUP NO.}

1

2

3

4

5

6

7

8

9

10

11

12

13

14

15

16

17

18

19

20

21

22

23

24

25

26

27

\section{GROUP LIPPER ENERGY}

$1.49 \cdot 10^{7}$

$1.35 \cdot 10^{7}$

$1.22 \cdot 10^{7}$

$1.00 \cdot 10^{7}$

$7.41 \cdot 10^{6}$

$5.49 \cdot 10^{6}$

$3.68 \cdot 10^{6}$

$2.23 \cdot 10^{6}$

$1.35 \cdot 10^{6}$

$8.21 \cdot 10^{5}$

$4.98 \cdot 10^{5}$

$3.02 \cdot 10^{5}$

$1.83 \cdot 10^{5}$

$1.11 \cdot 10^{5}$

$4.09 \cdot 10^{4}$

$1.50 \cdot 10^{4}$

$5.53 \cdot 10^{3}$

$2.03 \cdot 10^{3}$

$7.49 \cdot 10^{2}$

$2.75 \cdot 10^{2}$

$1.01 \cdot 10^{2}$

$3.73 \cdot 10^{7}$

$1.37 \cdot 10^{1}$

$5.04 \cdot 10^{0}$

$1.86 \cdot 10^{0}$

$6.80 \cdot 10^{-1}$

$4.10 \cdot 10^{-1}$

$1.00 \cdot 10^{-5}$
LETHARGY WIDTH

0.1

0.1

0.2

0.3

0.3

0.4

0.5

0.5

0.5

0.5

0.5

0.5

0.5

1.0

1.0

1.0

1.0

1.0

1.0

1.0

1.0

1.0

1.0

1.0

1.0

0.5 


\subsection{GROUP CONSTANTS EVALUATION MODELS}

Throughout the calculation three different group constants evaluation models were used, representing different levels of resonance self-shielding, to generate effective cross sections for the transport calculations. These models are:

1. Infinitely dilute group constants

2. Homogeneous medium resonance self-shielding

3. Heterogeneous medium resonance self-shielding

In this section a short description of the motivation and basic theory for each model will be presented.

\subsection{INFINITELY DILUTE MODEL}

In the framework of this model one completely neglects the resonance self-shielding effects. All cross sections assume their infinite dilute value, representing the 7 imit of background macroscopic cross section dominance where no influence on the flux can be detected due to localized (energy and space) resonance. The energy group cross sections are calculated by energy group averaging using a standard non-resonant flux as a weight function. This standard flux includes the fusion and fission peaks super imposed on an inverse energy dependent flux.

\subsection{HOMOGENEOUS MEDIUM SELF-SHIELDING MODEL}

This model takes into account the finite dilution of the resonance absorbers and assumes a homogeneous medium. The motivation for this model hinges on the observation that a resonance peak in the cross section of finite dilute material, at a certain energy, will cause a dip in the flux which does not occur in. the infinitely dilute case. As a result, the actual reaction rate will be lower. This model defines a new set of effective group constants which should produce more accurate reaction rates. The theory used to implement these ideas is the Bondarenko resonance self-shielding technique. ${ }^{4}$ 
This technique is based on pre-calculated self-shielding factors which correspond to different values of effective background cross sections (calculated from all other materials except that in question), which by multiplying the infinitely dilute cross section of the resonant material produces the approximate effective cross section.

\subsection{HETEROGENEOUS MEDIUM SELF-SH IELDING MODEL}

This model takes into account the heterogeneous nature of the medium as well as the finite dilution of the treated materials. The motivation for this model stems from the fact that in actual reactor design the resonant materials are usually lumped and placed in some lattice structure. The self-shielding phenomenon discussed in the homogeneous medium self-shielding model depends, in this model, on the spacial details as well. Again, as in the previous model, the self-shielding treatment is based on the Bondarenko technique. The heterogeneous effects are treated, utilizing the equivalence theorem of resonance calculations, with Dancoff corrections included. ${ }^{5}$ 


\subsection{BOL FUEL BLANKET}

Two fuel cycles are considered in this section, Th/U-233 and U/Pu-239 cycles. In both cases $\mathrm{BOL}$ fuel is used: pure $\mathrm{Th}-232$ and $\mathrm{UO}_{2}$ containing $0.25 \% \mathrm{U}-235$ tails respectively. Water, steam, and He coolants are considered. Each fuel cycle is analyzed using the various self-shielding treatments. A summary of blanket performance and neutron balance for Th/U-233 and U/Pu-239 fuel cycles is presented in Tables 4-1 and 4-2 respectively. Both tables are divided into three major parts: list of neutron sources, list of absorption processes and leakage, and general blanket performance features. All neutronic processes result from one fusion neutron and are obtained by summation over the entire energy and spacial ranges. In addition to the primary source, the fusion neutron, there are secondary neutron-generating processes, $(n, 2 n)(n, 3 n)$ and fission reactions. The absorption processes include absorption in fuel as well as absorption in other materials. The entry "absorption in other materials" is the sum of absorption in the moderator, clad, structure, reflector and shield. The "shield right leakage" is the total leakage from the hybrid reactor. "Blanket right leakage" is the total leakage from the blanket to the reflector. The "multiplication factor" is defined as the total energy output, per neutron from plasma, (total fission energy plus fusion neutron energy) divided by the fusion neutron energy. The fission output energy and fusion neutron energy were taken to be respectively 200 and $14.1 \mathrm{MeV}$. The "net fissile material production" is defined as:

(net fissile material production) $=$

(total fissile material production) -

(total absorption in fissile material)

Table 4-3 represents the resonance integral values for Th and $U-238(n, \gamma)$ reactions for the various self-shielding model-fuel-coolant combinations. For comparison purposes, only one temperature was used $\left(900^{\circ} \mathrm{K}\right)$. The various resonance integral values were obtained by summing up the effective cross sections in the appropriate resonance energy range (see Table 2-5, also note that the lethargy width in the resonance energy range equals 1.0 ). 
Th/U-233 CYCLE: BLANKET PERFORMANCE AND NEUTRON BALANCE PER NEUTRON

EMITTED FROM PLASMA FOR VARIOUS MODERATIONS AND SELF-SHIELDING TREATMENTS

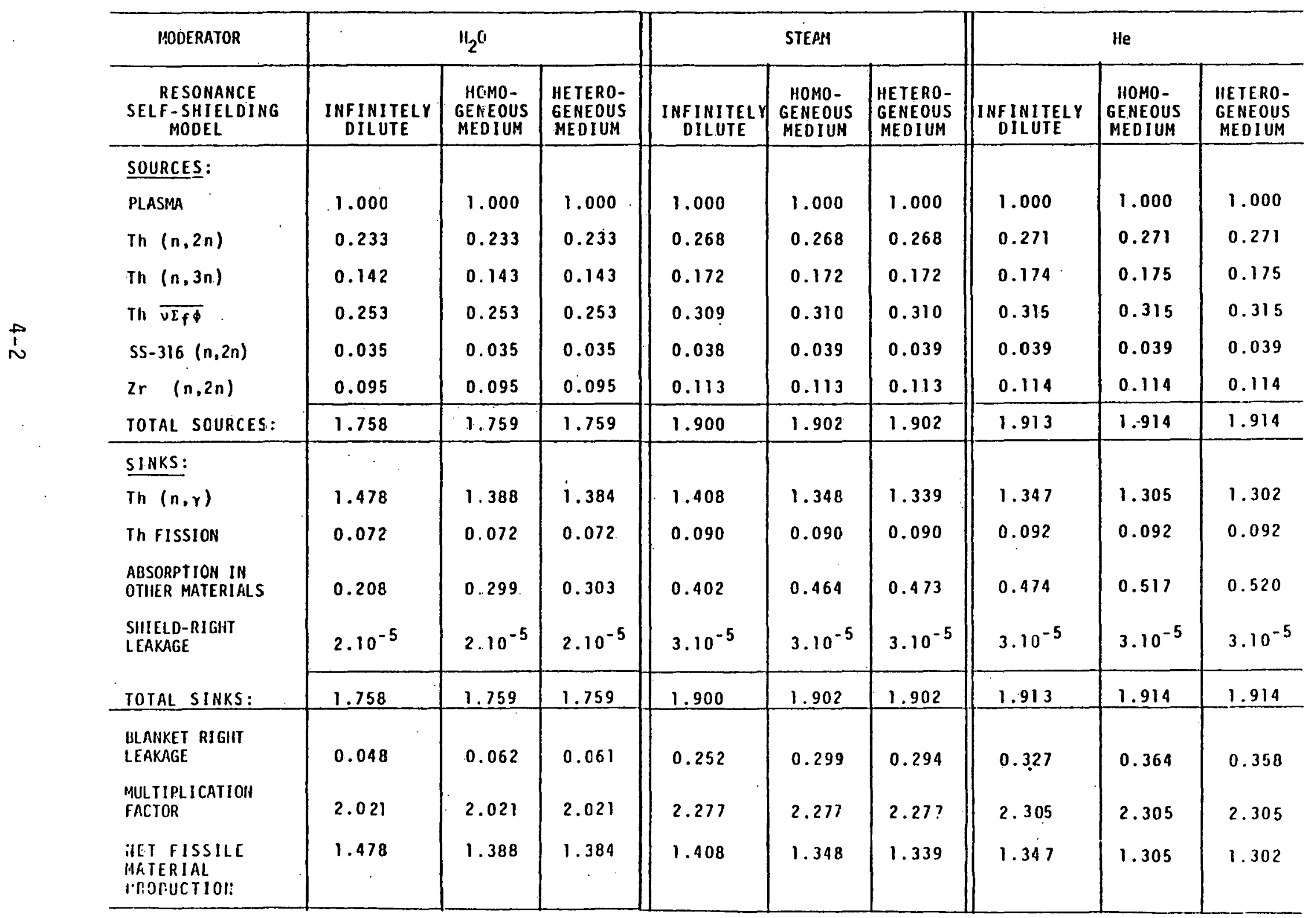


TABLE 4-2

U/PU-239 CYCLE: BLANKET PERFORMANCE AHD NEUTRON BALAMCE PER NEUTRON EMITTED FROM PLASMA FOR VARIOUS MODERATORS AND SELF-SHIELDING TREATMENTS $(0.25 \%$ U-235 TAILS)

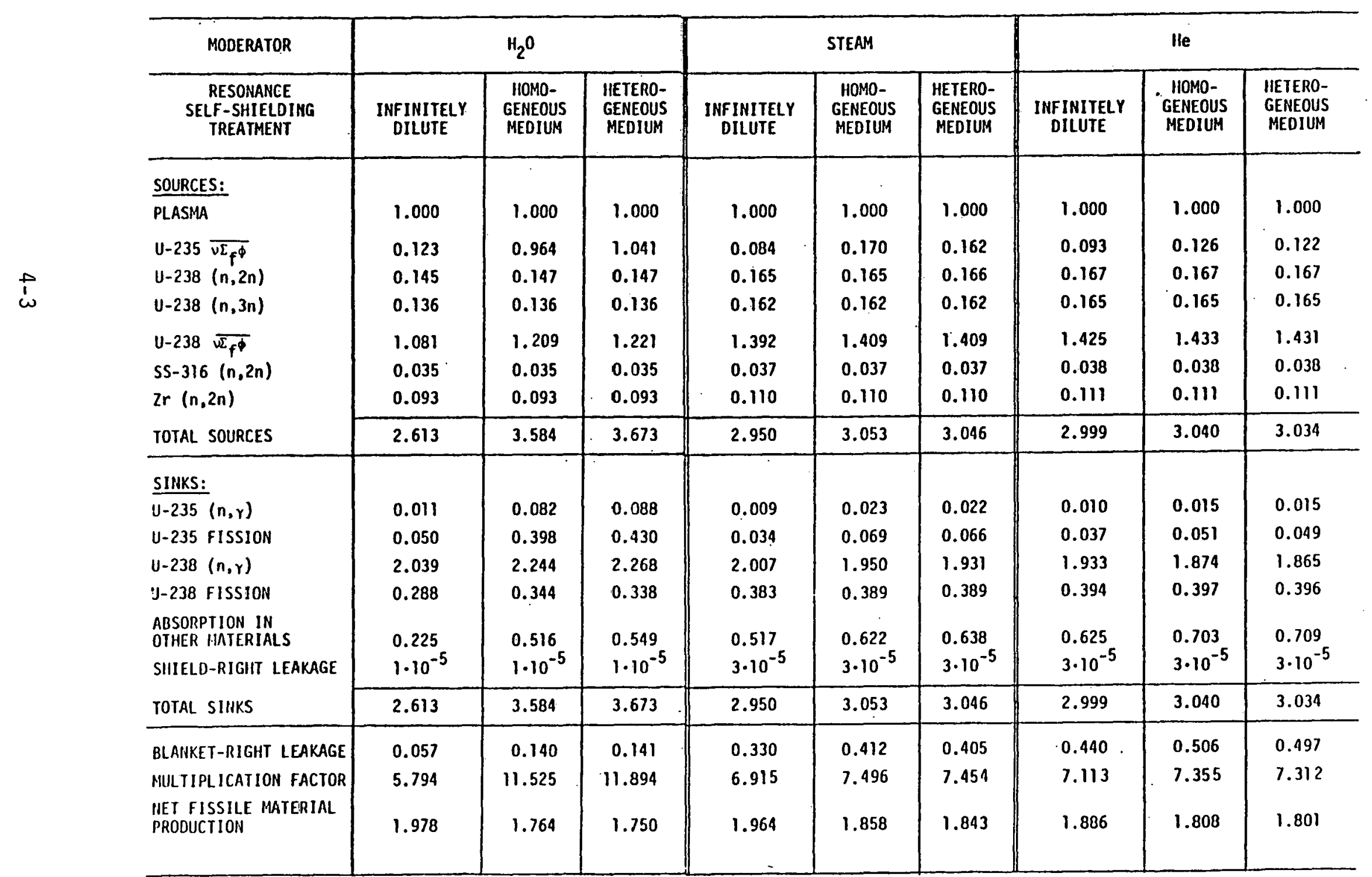


TABLE 4-3

RESONANCE INTEGRAL VALUES FOR Th-232 AND U-238 $(n, \gamma)$ REACTIONS FOR VARIOUS SELF-SHIELDING TREATMENTS (IN BARNS)

\begin{tabular}{|c|c|c|c}
\hline $\begin{array}{c}\text { BLANKET SELF-SHIELDING } \\
\text { COMBINATION }\end{array}$ & $\begin{array}{c}\text { INFINITELY } \\
\text { DILUTEE }\end{array}$ & $\begin{array}{c}\text { HOMOGENEOUS } \\
\text { MEDIUM }\end{array}$ & $\begin{array}{c}\text { HETEROGENEOUS } \\
\text { MEDIUM }\end{array}$ \\
\hline $\mathrm{ThO}_{2}-\mathrm{H}_{2} \mathrm{O}$ & 83.1 & 13.1 & 11.6 \\
$\mathrm{ThO}_{2}-\mathrm{STEAM}$ & 83.1 & 9.6 & 9.5 \\
$\mathrm{ThO}_{2}-\mathrm{He}$ & 83.1 & 9.2 & 9.2 \\
$\mathrm{UO}_{2}-\mathrm{H}_{2} \mathrm{O}$ & 276.6 & 21.0 & 18.9 \\
$\mathrm{UO}_{2}-$ STEAM & 276.6 & 16.5 & 16.3 \\
$\mathrm{UO}_{2}-\mathrm{He}$ & 276.6 & 16.1 & 16.0 \\
\hline
\end{tabular}

The various figures in this section (Figures 4-1 to 4-12) present detailed reaction rates, per $\mathrm{cm}^{3}$, per neutron from $\mu 1$ asima, as function of radial position in blanket, for the important processes, using various resonance self-shielding treatments, coolants and fuel. The steam-cooled blanket case is omitted occasionally because of its intermediate nature. The results, presented in the tables and figures mentioned above, will be discussed throughout this section. 


\subsection{INFINITELY DILUTE MODEL}

\subsubsection{Th/U-233 CYCLE}

The primary source of neutrons, the plasma, produces $14.1 \mathrm{MeV}$ neutrons which, in turn, produce a secondary source by inducing $(n, 2 n)$ processes in the stainless steel, zircalloy and $\mathrm{ThO}_{2}$, and $(n, 3 n)$ and fission processes in the $\mathrm{ThO}_{2}$. This secondary source is composed of fast neutrons (neutron energy above $? \mathrm{MeV}$ ) and is supplied mainly by the blanket, therefore, it is sensitive to the kind of moderation used. As the moderation properties decrease (water through steam to $\mathrm{He}$ ), the flux spectrum becomes harder. This implies higher total source in the poorer moderated blanket (see Table 4-1).

The U-233 production rate, as a function of the radial position in the blanket, is presented in Figure 4-1. It depends on the neutron energy spectrum, particularly in this model, due to the high cross-section values in the resonance region ( $1 \mathrm{eV}$ to $5 \mathrm{KeV}$ ). This dependence is reflected clearly by the different reaction rate shapes corresponding to the various moderators. The water-cooled blanket case exhibits a softer flux spectrum compared to the He case. This induces a higher neutron population, for small blanket radii, in the resonance energy range and, therefore, higher Th $(n, \gamma)$ reaction rate. At greater depths in the blanket, the water-cooled case is over-moderated with regard to the resonance energy range, and the U-233 production for the $\mathrm{He}$ cooled blanket is higher. The far region of the hlanket exhibits a peak in the U-233 production rate, which indicates a peak in the resonance energy groups flux. This is due to the slowing down process, in the reflector, of fast neutrons escaping from the blanket. Due to the harder spectrum for the He cooled blanket case and the higher leakage from the blanket to the reflector, the peak is more pronounced in the He case. It is not surprising, following the above discussion, that the total $U 233$ production rate increases with an increase in moderation properties (see Table 4-1) at BOL. The steam cooled blanket is an intermediate case between the water and He cooled blankets, as far as moderation and flux spectrum, and from Figure 4-1 it clearly behaves as such. 


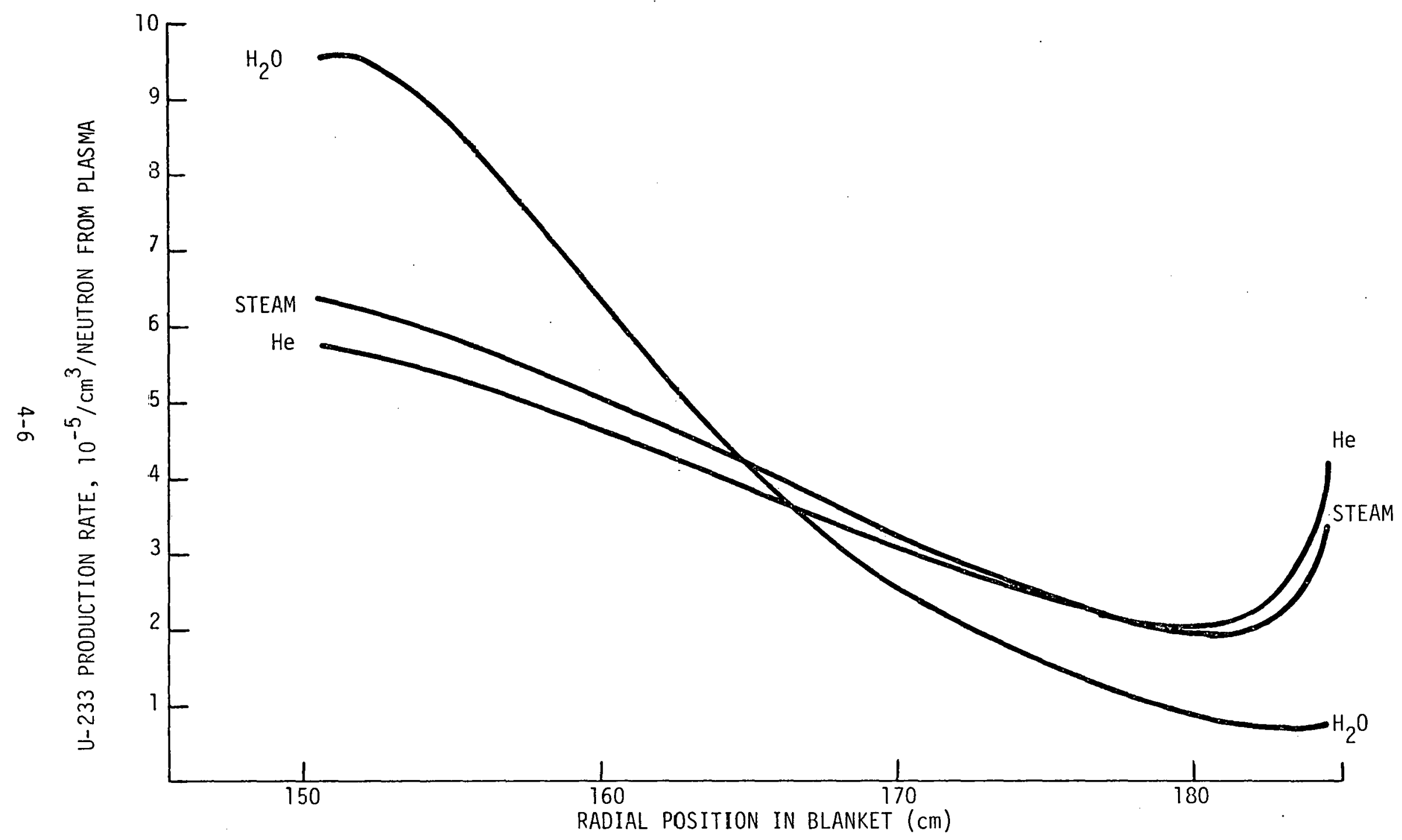

FIGURE $4-1$. U-233 PRODUCTION RATE, PER $\mathrm{cm}^{3}$, PER NEUTRON FROM PLASMA, FOR VARIOUS COOLANTS, USING INFINITELY DILUTE MODEL 
4.1.2 U/PU-239 CYCLE

The $\mathrm{UO}_{2}$ fuel contained $0.25 \% \mathrm{U}-235$ tails, therefore, in addition to the neutron sources mentioned in section 4.1 .1 , one has to consider the U-235 fission source caused mainly by thermal neutrons. However, we will start the discussion with the relatively simple U-238 fission process. The fission rate for the water and He cooled blankets is given in Figure 4-2. The lack of a fission peak near the reflector boundary indicates that only high energy neutrons are responsible for fissions in U-238 for the same reason the total U-238 fission rate is higher for the He case (see Table 4-2). The steam cooled blanket case is an intermediate case between the water and He cases. The U-235 fission source is represented in Figure 4-3. The water cooled blanket case follows the lowest energy group flux behavior due to good moderation of the water and the high thermal fission cross-section of $U-235$. The absence of a peak near the reflector is due to the suppression of the fast flux in the reflector by the good moderation of the water in the blanket. The He and steam cases show overall less fission due to harder spectrum, however, the relative relations between the two are more complicated. There are two competing effects: a) total flux ratio and b) thermal flux ratio. At small depths in the blanket, the overall flux is higher for the He case because of more fissions in the U-238 (harder spectrum) and the thermal flux is higher for the steam case. It turns out that the total flux is dominant and, therefore, more fissions occur in the He case. At greater depths in the blanket there is a higher total flux due to a higher $U-238$ fission rate in the He case and also higher thermal flux due to the diffusion of thermal neutrons from the reflector, therefore, the U-235 fission rate difference is even more pronounced. The total source goes down as a function of moderation (higher in the He casc) as in the Th0, blanket and the U-235 tails have a small effect on the neutron balance in the infinity dilute model.

The Pu-239 production rate considerationsare similar to those of the U-233 production rate in general. The differences are due to the resonance energy 


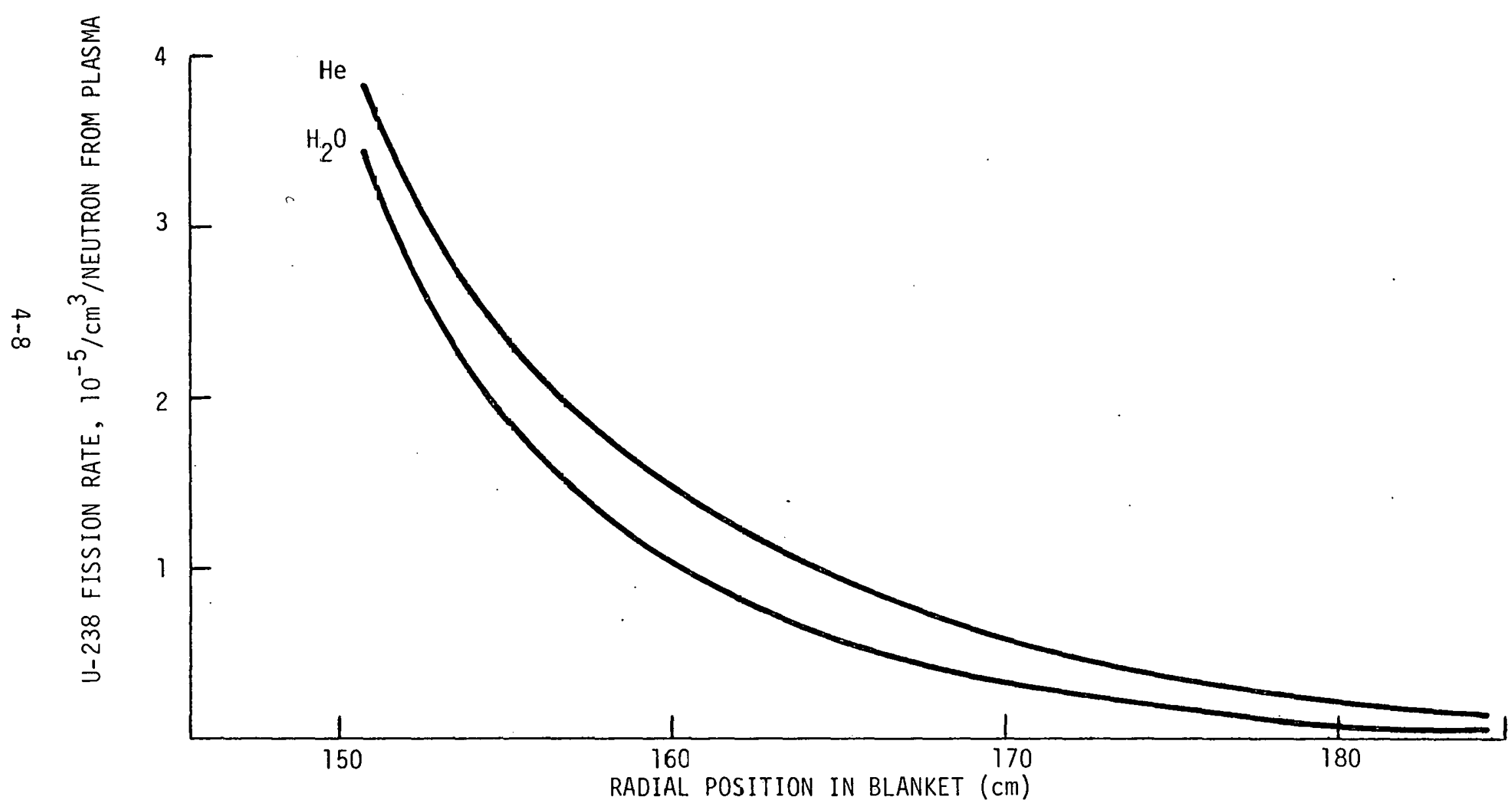

FIGUFE 4-2. II-238 FISSION RATE, PER $\mathrm{cm}^{3}$, PER NEUTRON FROM PLASMA IN $\mathrm{H}_{2} \mathrm{O}$ AND He COOLED BLANKETS, USING INFINITELY DILUTE MODEL 


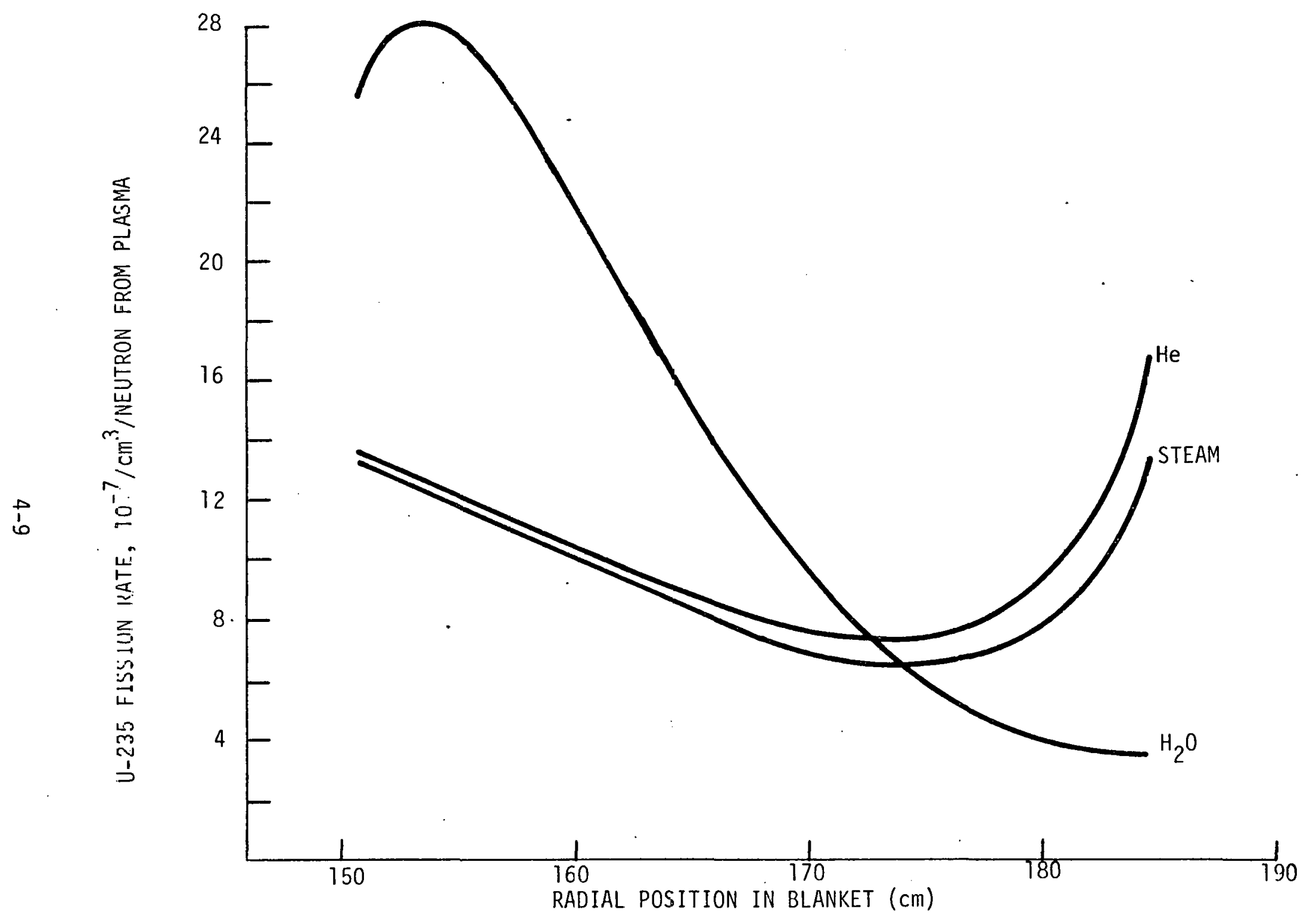

FIGURE 4-3. U-235 FISSION RATE, PER $\mathrm{cm}^{3}$, PER NEUTRON FROM PLASMA

FOP VARIOUS COOLANTS USING INFINITELY DILUTE MODEL 
range, and mostly, the cross-section values of the resonances. For the U-238 $(n, \gamma)$ process the range is wider and the cross-section values are larger by a factor of three. All features of the fissile production are more pronounced as can be seen from Figure 4-4 compared to Figure 4-1 (e.g. back peak for the three coolants).

\subsection{HOMOGENEOUS MEDIUM SELF-SHIELDING MODEL}

This model predicts lower energy group constants values, for the resonance absorbing materials, than those used in the infinitely dilute model (see Table 4-3 for various resonance integral values). Higher resonance escape probabilities are expected, therefore, less absorption in Uranium or Thorium and more absorption in structure material and coolant. Moreover, because of the relatively lower effective cross-sections values the reaction rate spectrum, as a function of radial position in the blanket, is expected to exhibit smaller relative changes. These remarks are generally true, however, the situation is more complicated if fissile material is introduced as in the $\mathrm{UO}_{2}$ blanket. These new features will be discussed in section 4.2 .2 .

\subsubsection{TH/U-233 CYCLE}

The source description for the infinitely dilute model can be repeated for this model, due to the following observations.

a) The secondary source $((n, 2 n)(n, 3 n)$ and fission reactions) is generated by fast neutrons $\left(E_{n}>I M e V\right)$.

b) The self-shielding treatment cause major changes only in the resonance energy range $\left(E_{n}<5 \mathrm{KeV}\right)$, for the Thorium absorption cross-section. As a result, the finite dilution self-shielding effects are almost completely isolated from the neutron sources. From Table 4-1 it can be seen that the differences between this model and the infinitely dilute model are less than $0.1 \%$ for each source generating process and the total source.

The U-233 production rate is reduced due to self-shielding effects, causing the absorption in the structure material and coolant to increase. (As mentioned

previously, the total source is almost unchanged. Adding the fact that leakage is negligible results in actually constant total absorption). The U-233 


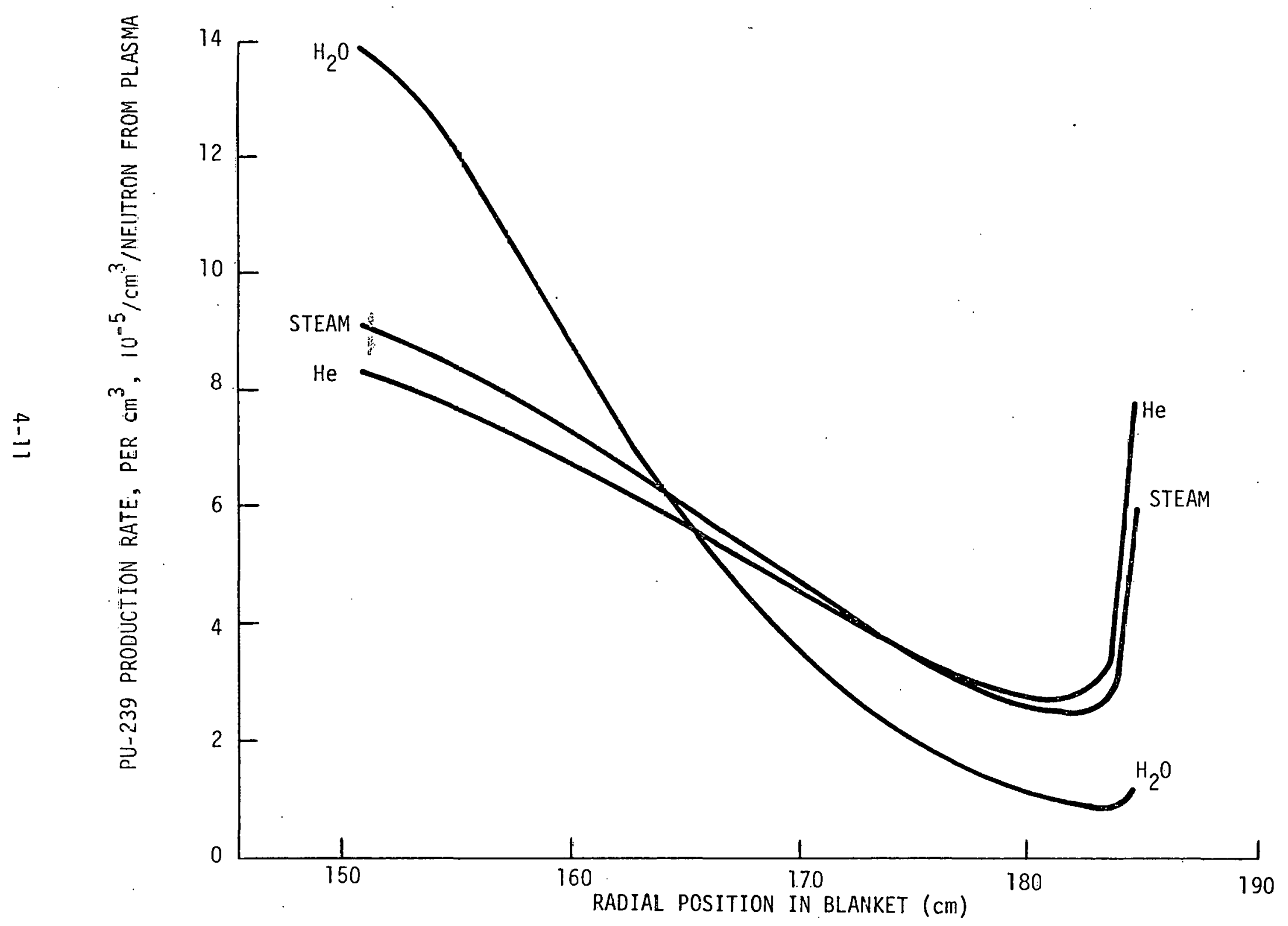

FIGURE 4-4. PU-239 PRODUCTIGN RATE, PER $\mathrm{cm}^{3}$, PER NEUTRON FROM PLASMA, FOR VAR.IOUS COOLANTS, USING INFINITELY DILUTE MODEL 
spacial distribution production rate is shown in Figure 4-5 for the different coolants. The flattening of the reaction rate curves, compared to those in the infinitely dilute model, can be seen in Figure 4-6 where a comparison, for water and He cooled blankets, between the two models is presented.

\subsubsection{U/PU-239 CYCLE}

As mentioned earlier, there are new features, not encountered in the Th/U-233 cycle, due to the presence of fissile material, namely U-235, in the $\mathrm{UO}_{2}$ case blanket. The U-235 fissions serve as secondary source, however, contrary to the Th-232 and U-238, these fissions are caused by thermal neutrons. The effective reduction of the absorption cross-section, in the U-238 resonance energy range, enables more fast neutrons to reach thermal energies, therefore, increasing the U-235 fission rate markedly. This effect is most pronounced in the water cooled blanket because of its good moderation properties. The overall fission rate increases for the water, steam, and He cooled blanket cases by roughly $700 \%, 100 \%, 40 \%$ respectively as shown in Table 4-2. The homogeneous medium self-shielding results for U-235 fission rate as a function of radial position in the blanket are shown in Figure 4-7. In contrast to the infinitely dilute model, the fission rate for the steam case is higher than for the He case, a change which obviously is a result of the better moderation properties of the steam compared to those of the He. Comparison for water and He cooled blankets, between the two models is shown in Figure 4-8.

The basic shape of the U-238 spacial distribution fission rate is conserved: However, due to higher neutron densities, especially in the water cooled blanket case, the U-238 fission rate is higher, as compared to the infinitely dilute model (see Figure $4: 9$ ).

The $\mathrm{Pu}-239$ total production rate is sensitive to the kind of moderation used in the blanket. The He cooled blanket does not supply many thermal neutrons to the U-235 fission process, therefore, the overall neutron population (total sources) does not increase enough in order to overcome the decrease in Pu-239 production due to lower effective cross-section in the $U-238$ resonance energy range (see Table 4-2). However, in the water cooled blanket case, the overa 11. 


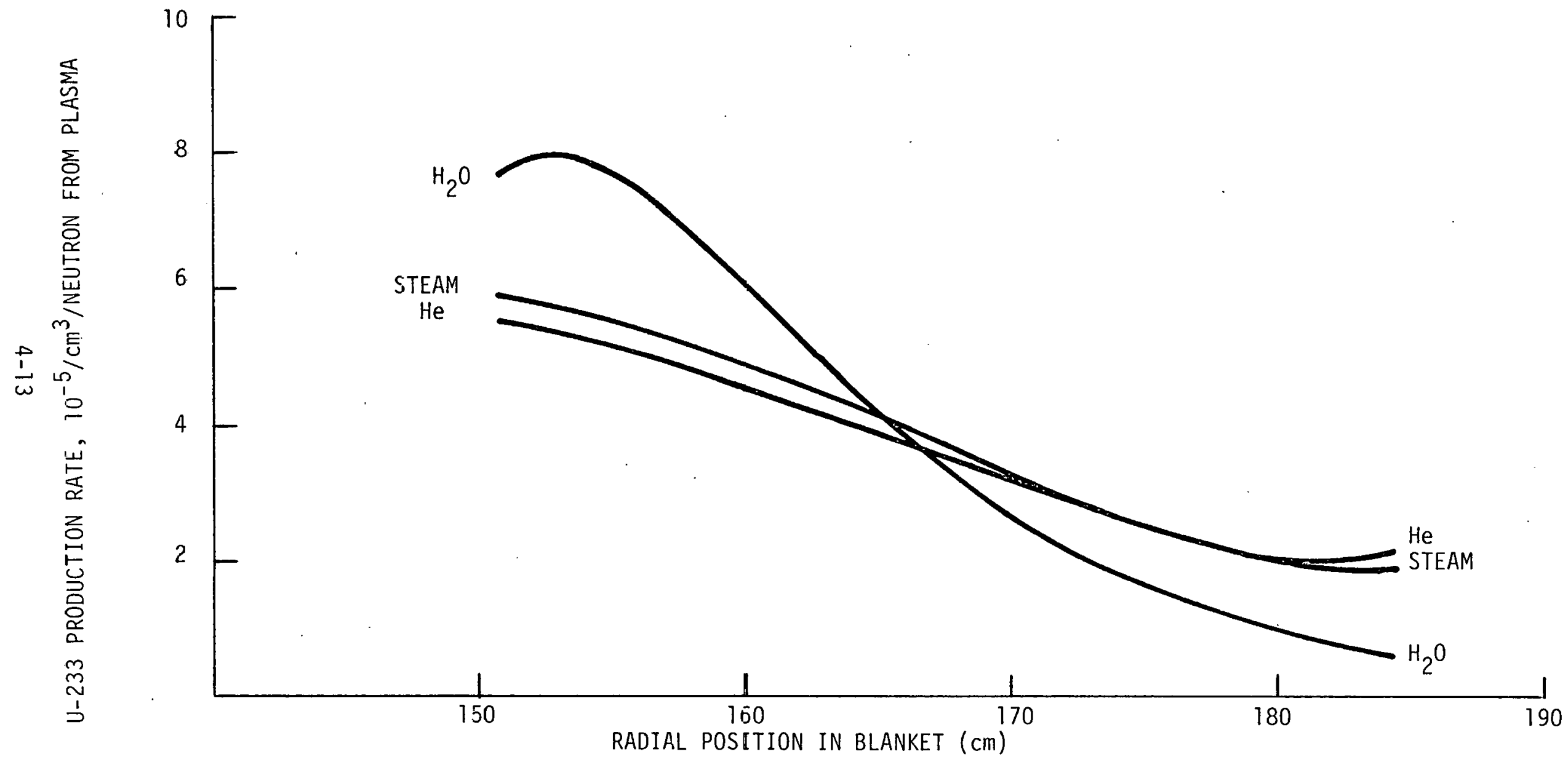

FIGURE 4-5. U-233 PRODUCTION RATE, PER $\mathrm{cm}^{3}$, PER NEUTRON FROM PLASMA, FOR VARIOUS COOLANTS, IJSING HOMOGENEOUS MEDIUM SELF-SHIELDING MODEL 


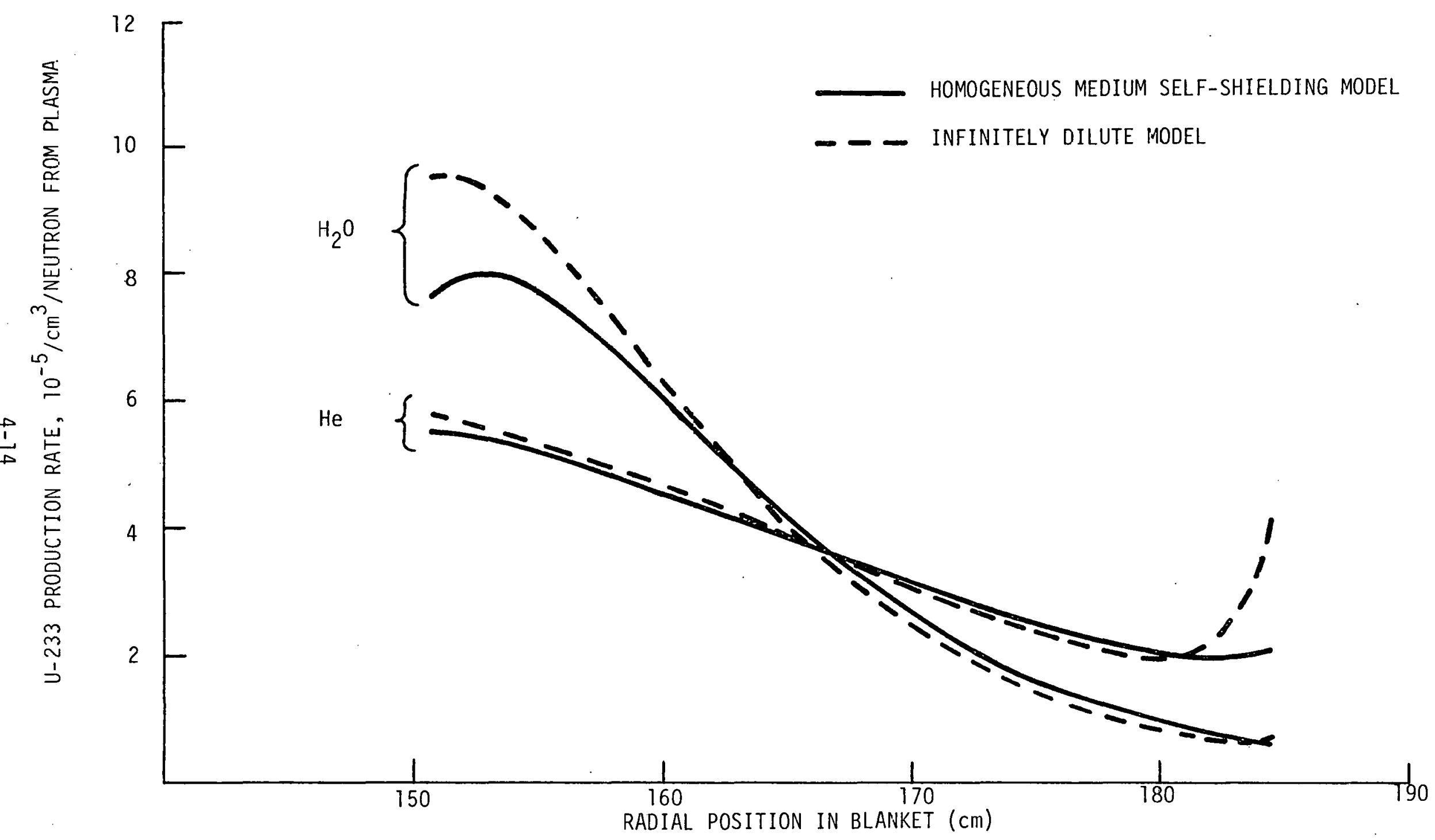

FIGURE 4-6. COMPARISGIN OF U-233 PRODUCTION RATE, PER CIII ${ }^{3}$, PER NEUTRON FROM PLASMA, BETWEEN HOMOGENEOUS MEDIUM SELF-SHIELDED AND INFINITELY DILUTE TREATED BLANKETS, COOLED BY HE AND $\mathrm{H}_{2} \mathrm{O}$ 


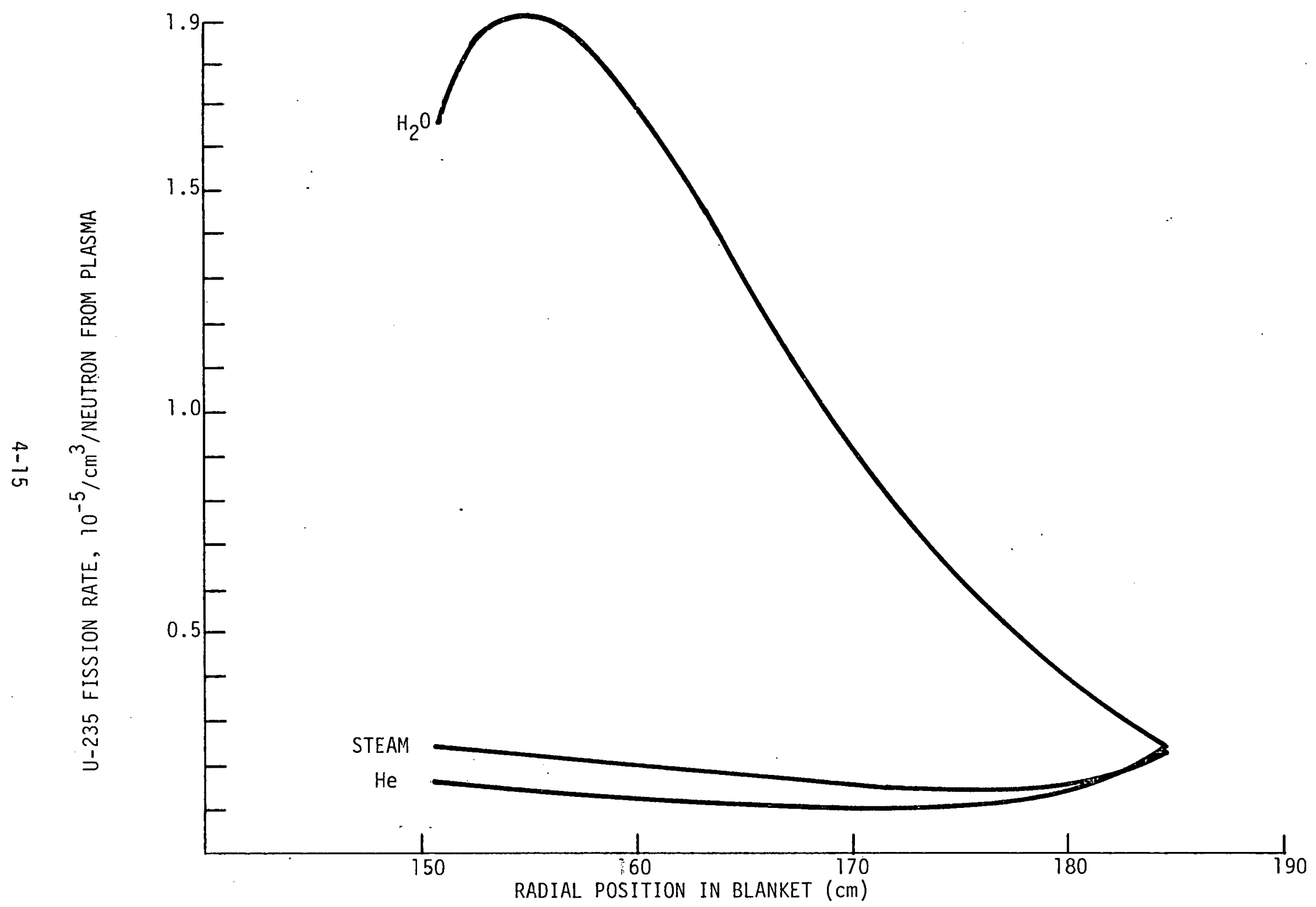

FIGURE 4-7. U-235 FISSION RATE, PER $\mathrm{cm}^{3}$, PER NEUTRON FROM PLASMA FOR VARIOUS CDOLANTS USING HOMOGENEOUS MEDIUM SELF-SHIELDING MODEL 

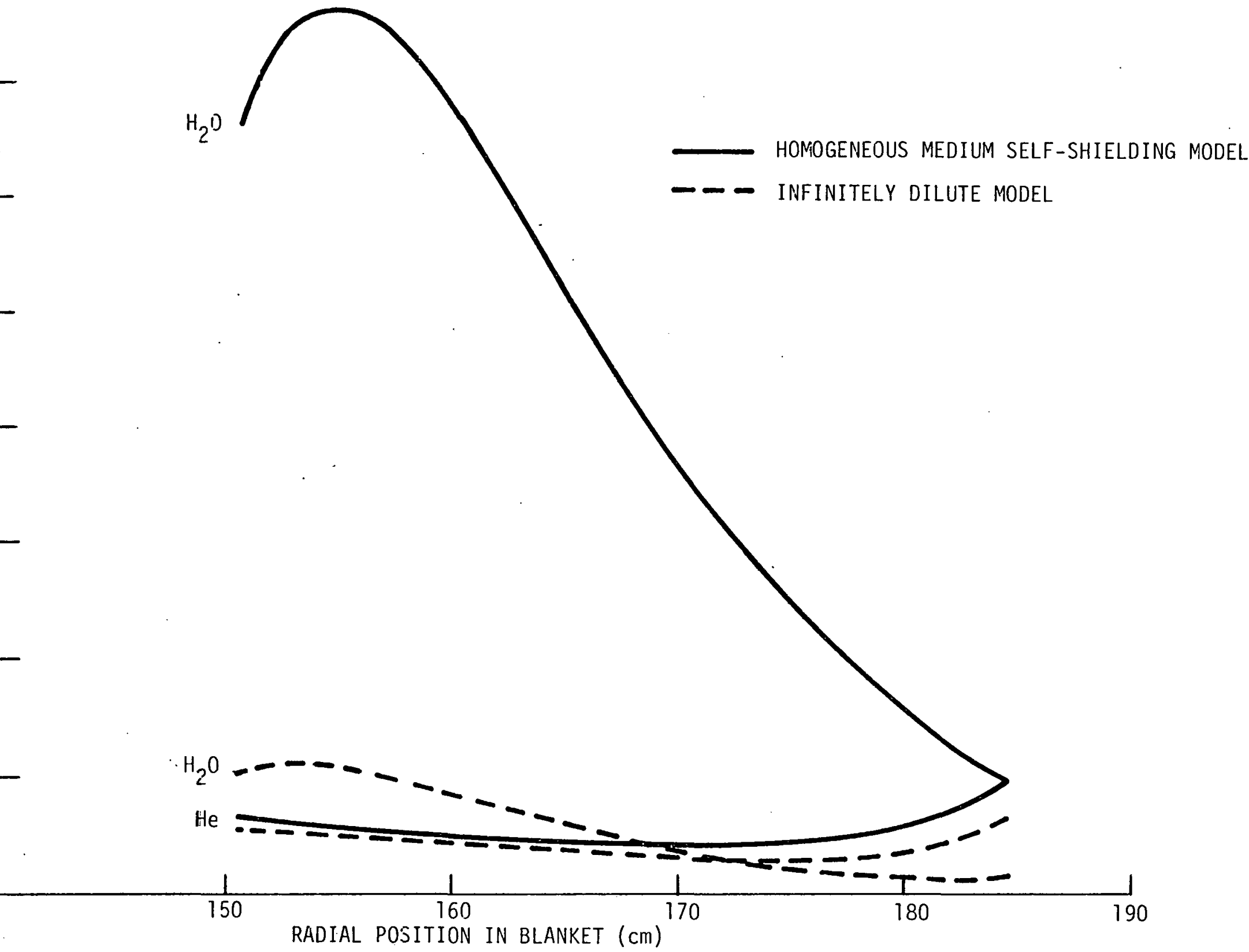

FIGURE 4-8. COMPARISON OF U-235 FISSION RATE, PER $\mathrm{cm}^{3}$, PER NEUTRON FROM PLASMA BETWEEN HOMOŚENEOUS MEDIUM SELF-SHIELDED AND INFINITELY DILUTE TREATED BLANKETS COOLED BY He and $\mathrm{H}_{2} \mathrm{O}$ 


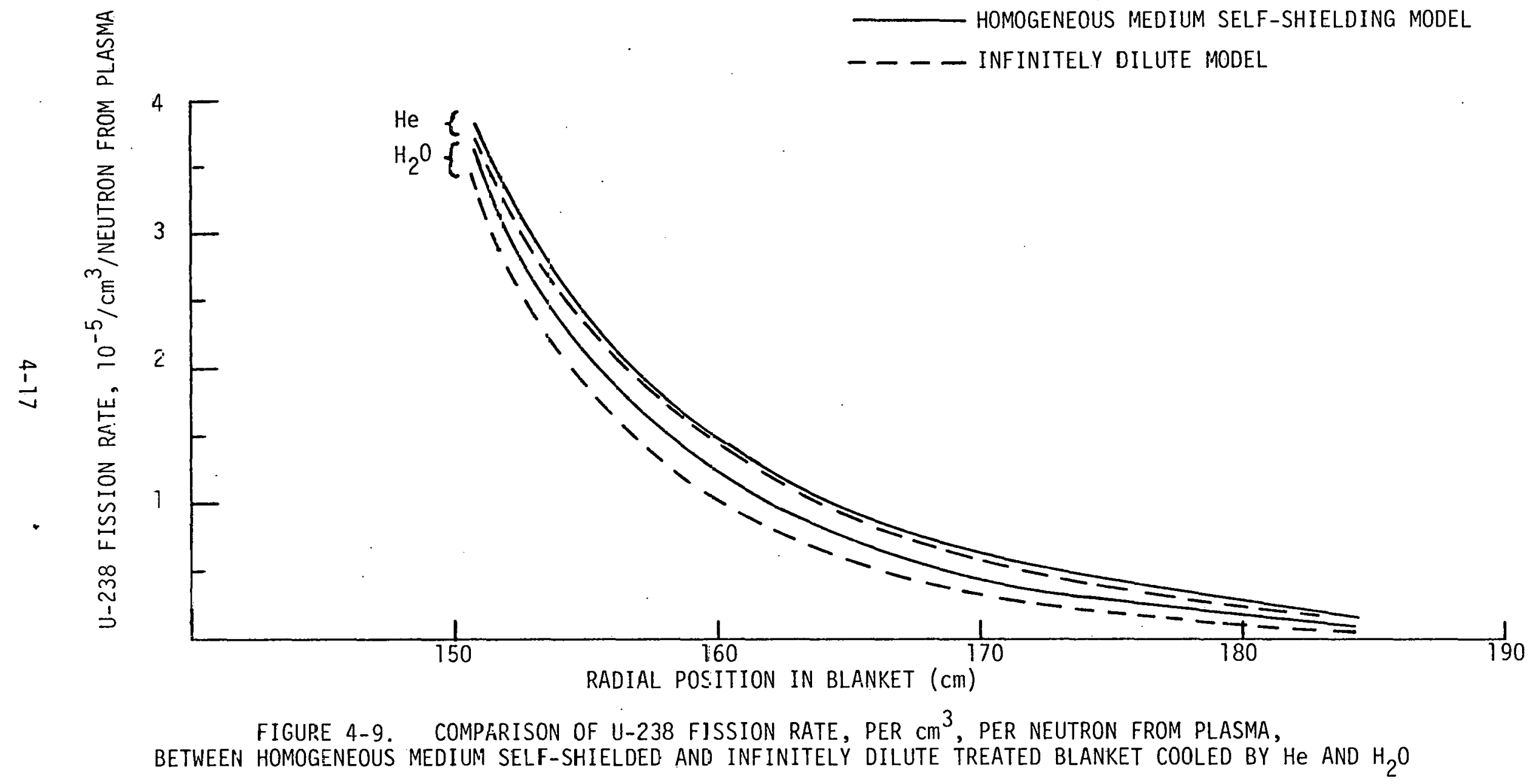


neutron population increases compared to the infinitely dilute model, by $40 \%$, causing an increase in the Pu-239 production despite lower effective cross sections. Figure 4-10 shows the $U-238(n, y)$ reaction rate as a function of radial position in the blanket for the various coolants. Figure 4-11 is a comparison for water and He cooled blankets between the two models. Once more, the finite dilution self-shielding effects (e.g., flatter spectrum, lower back peak) emerge clearly from this figure.

\subsection{HETEROGENEOUS MEDIUM SELF-SHIELDING MODEL}

This model takes into account the absorber finite dilution, as well as the medium spacial self-shielding effects. When analyzing the results calculated using this model, and comparing them to previous results, the following facts should be kept in mind.

a) The fuel and coolant temperatures used in this model were $900^{\circ} \mathrm{K}$ and $550^{\circ} \mathrm{K}$ respectively where an average temperature of $666^{\circ} \mathrm{K}$ was used in the homogeneous medium model. Effective cross-sections are expected to differ, using these two models, due to fuel temperature difference.

b) The $\mathrm{Zr}$ was self-shielded in the homogeneous medium case, however, its infinite dilute cross-section values were used in this model (this was done for reasons not relevant to this set of calculations and under the assumption that the different self-shielding treatment of the $\mathrm{Zr}$ will induce negligible errors in the overall blanket performance).

Generaliy, the pure spacial self-shielding effects have the same trends as the finite dilution self-shielding effects, however, the various results must be analyzed carefulty in view of the opening remarks.

\subsubsection{Th/U-233 CYCLE}

The source description for the infinitely dilute model is applicable for this model as well, following the same reasoning lines that were drawn in the homogeneous medium model, as emerged from the source description in Table 4-1.

The change in U-233 production rate (and as a complement, the absorption in other materials), relative to that in the homogeneous medium self-shielding model, seems to be rather small when compared to the difference in the U-233 production 


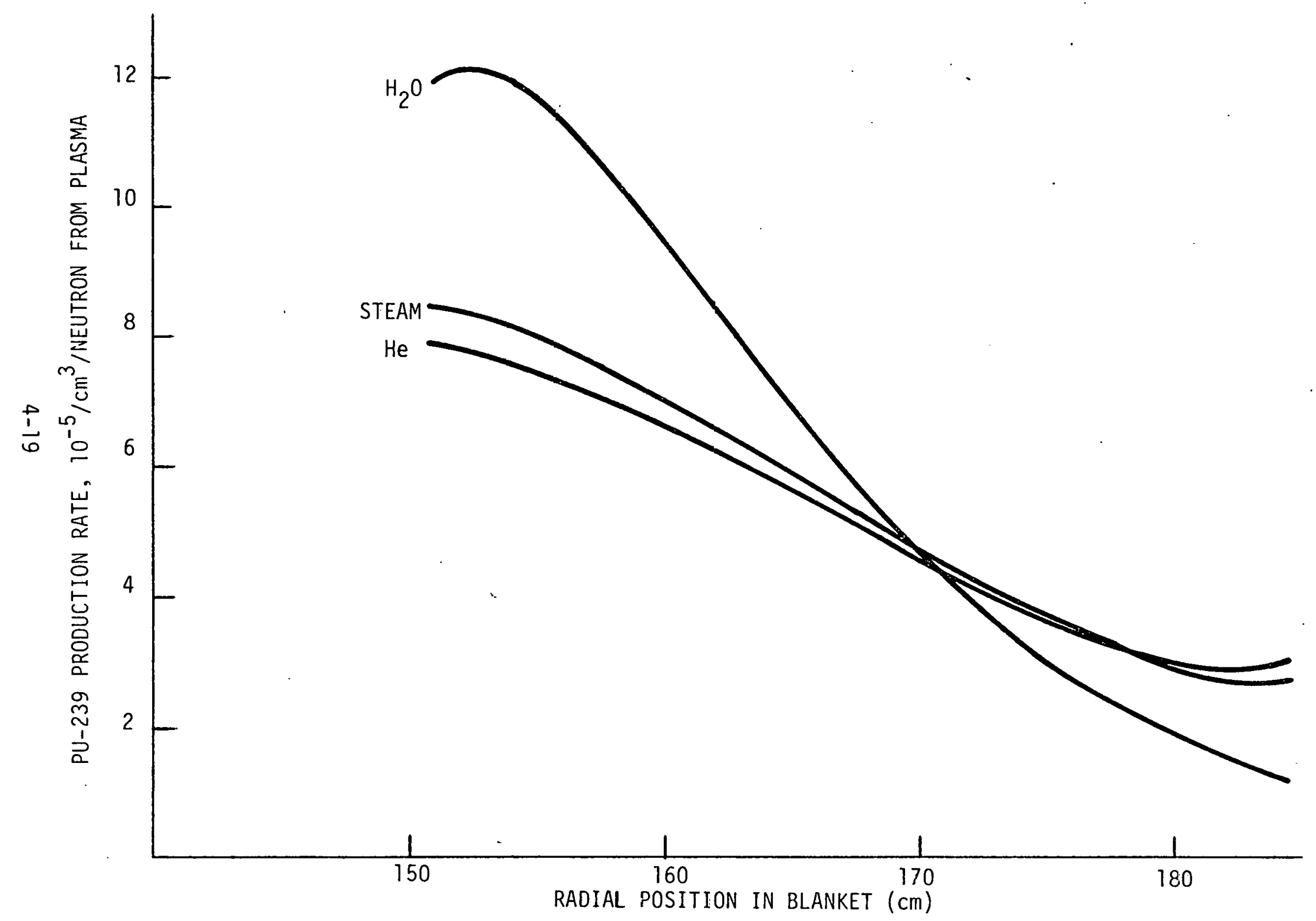

FIGURE 4-10. PU-239 PRODLCTION RATE, PER $\mathrm{cm}^{3}$, PER NEUTRON FROM PLASMA, FOR VARIOUS COOLANTS, USING HOMOGENEOUS MEDIUM SELF-SHIELDING MODEL 


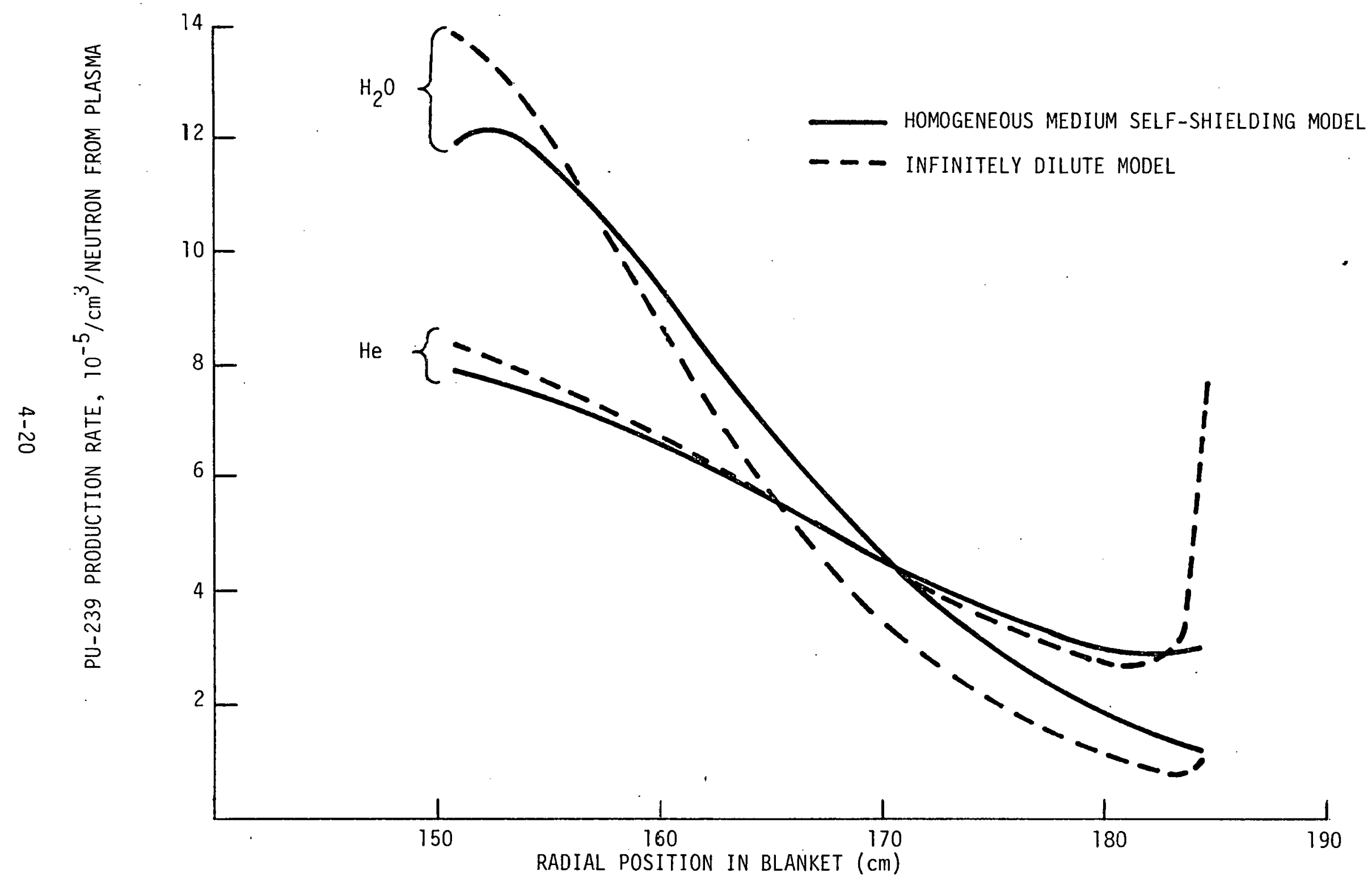

FIGURE 4-11. COMPARISIN OF PU-239 PRODUCTION RATE, PER $\mathrm{cm}^{3}$, PER NEUTRON FROM PLASMA, BETWEEN HOMOGENEOUS MEDIUM SELF-SHIELDED AND INFINITELY DILUTE TREATED BLANKETS, COOLED BY He AND $\mathrm{H}_{2} \mathrm{O}$ 
rate for the first two models. This trend is reasonable in view of the resonance integral values, for the different self-shielding models, given in Table 4-3. A more careful analysis of the Th $(n, \gamma)$ reaction rate, in the homogeneous and heterogeneous self-shielding models, reveals that changes due to different temperatures and $\mathrm{Zr}$ self-shielding treatments are comparable to changes due to the pure spacial effects.

\subsubsection{U/PU-239 CYCLE}

The steam and He cooled blanket exhibits the ambiguous behavior described in the last section: It turns out that temperature effects inherent in the modelirig are comparable or even higher than the pure spacial effects. In the water cooled blanket the temperature and $\mathrm{Zr}$ self-shielding effects are sma11, compared to the pure spacial effects, due to the good moderation properties of the water. For this reason, any further discussion will include solely the water cooled blanket case.

The source description, in general, and the U-235 fission process, in particular, follows the description outlined in the homogeneous medium self-shielding model. The lower effective U-238 absorption cross section, in this model, enhanced the trends, discussed in the previous model, of higher U-235 fission rate and higher total source (see Table 4-2). A comparison of U-235 fission rate, as a function of the radial position in the blanket, between the heterogeneous and homogeneous medium self-shielded blankets, is shown in Figure 4-12. (The heterogeneous case for steam and He cooled blankets is not presented because of the small and ambiguous change compared to the homogeneous case).

As in the homogeneous medium, the $\mathrm{Pu}-239$ production rate increases despite the lower effective cross-sections, due to higher total source. The Pu-239 pruduction rate difference between the two models is too small to be presented as a function of radial position in blanket.

\subsection{DISCUSSION}

\subsubsection{Th/U-233 CYCLE}

The most prominent feature of this blanket is the lack of fissile material, 


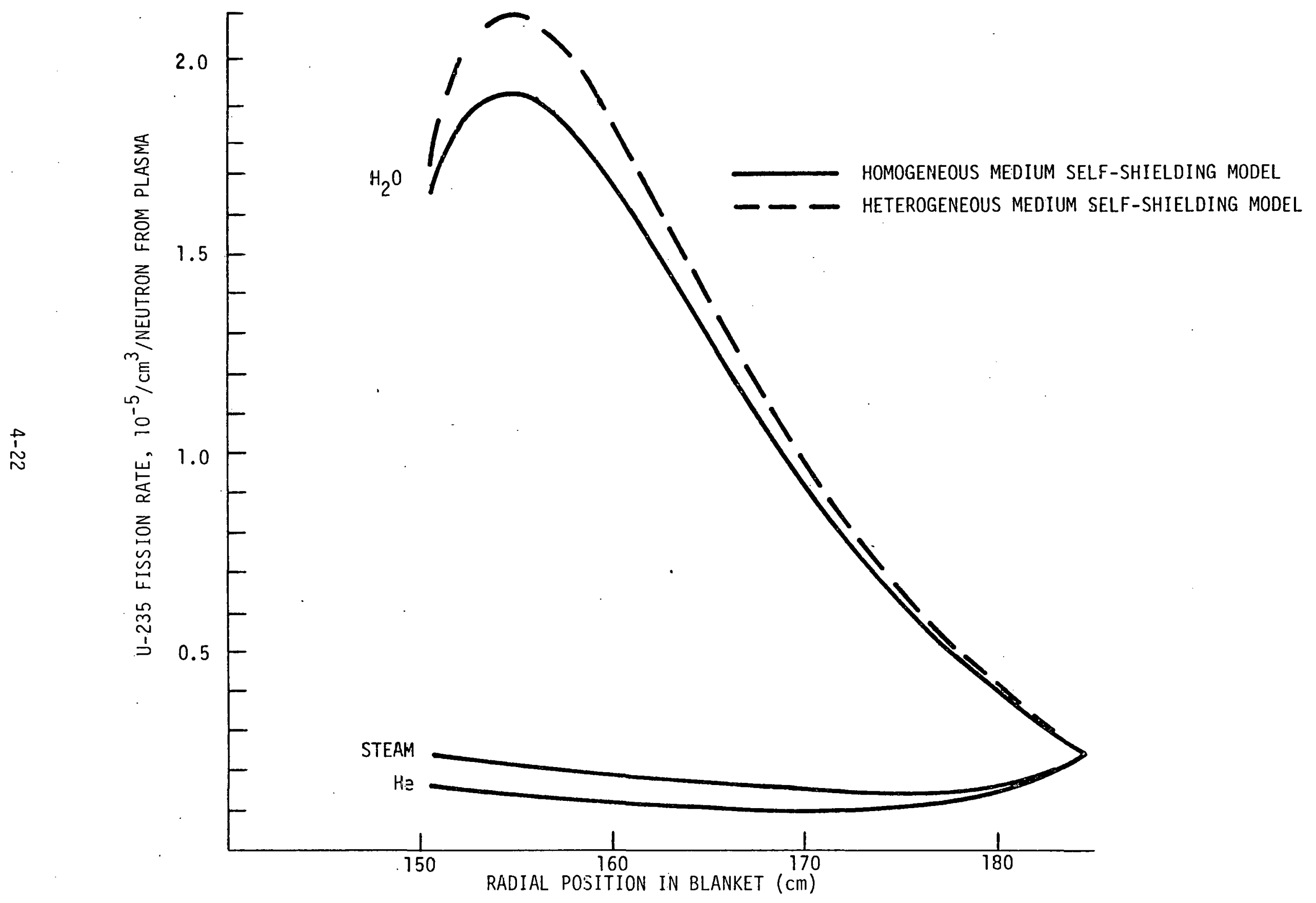

FIGURE 4-12. COMPARISIN OF U-235 FISSION RATE, PER $\mathrm{cm}^{3}$, PER NEUTRON FROM PLASMA, BETWEEN HOMOGENEOUS AND HETEROGENEOUS MEDIUM SELF-SHIELDED BLANKETS 
at beginning of life, which makes the analyses relatively simple. No fissile material implies high energy neutron sources which, as discussed earlier, are completely separated, energy-wise, from the resonance self-shielding treatments. The total source, for each coolant, is actually constant as shown in Table 4-1, however, the total source increases as the moderation properties decreases (from water to He) due to a combination of hard spectrum and high energy source generatina processes.

Neutron balance and negligible leakage from the system implies constant total absorption for each coolant, independent of the self-shielding treatment. For a given coolant, higher self-shielding level corresponds to lower effective Thorium absorption cross-section (see Table 4-3) which cause less absorption in the Thorium (and more absorption in all other materials). As moderation properties decrease and the spectrum gets harder, less absorption in Thorium occurs, due to the relative low energy range of the resonances. The U-233 production rate as a function of radial position in the blanket flattens with higher self-shielding levels.

The net fissile material production, due to the lack of fissile material, is identical to U-233 production. The multiplication factor values are independent of the resonance self-shielding treatment, for each coolant, following the insensitivity of the Thorium fission process to the various treatments. The moderation dependence of the multiplication factor is parallel to the Thorium fission rate dependence which, as part of the total source, was discussed above. The multiplication factor increases with decrease of moderation, properties. The harder spectrum corresponds to poorer moderation, causes higher leakage from the blanket to the reflector. Increase in resonance self-shielding level, for each coolant, causes more neutrons to leave the blanket and enter the reflector zone by lowering the absorption in the blanket.

In the absence of fissile material the resonance self-shielding effects are small, the main effect is due to the finite dilution of Thorium. The pure spacial effects are negligible and completely obscured by the different temperatures used in the various models. 


\subsubsection{U/PU-239 CYCLE}

The introduction of fissile material is necessary if analyses of realistic systems is desired. The $\mathrm{UU}_{2}$ fuel used in this case contains $0.25 \% \mathrm{U}-235$ tails. The simple picture, drawn in the last section, is complicated by the presence of a neutron source generated by thermal neutrons. The $U=235$. fission rate. is enhanced for better moderation properties and higher U-238 resonance self-shielding level. In both cases more neutrons can reach thermal energies and, therefore, cause fission in U-235. These trends can be seen clearly in Table 4-2. (Note that the heterogeneous medium self-shielded blankets cooled by steam and He suffer from uncertainties due to different fuel temperatures and $\mathrm{Zr}$ resonance selfshielding treatments). The $U-238$ fission rate is the only source generating process which depends on the U-235 fission rate. It increases with an increase in U-235 fission rate due to higher fast neutron population. The thermal source (U-235 fission) is more sensitive to changes in moderation and resonance self-shielding level than the fast neutron source, therefore, the total neutron source, while showing the same trends as the Th/U-233 cycle, in the infinite dilute model, has the opposite trends in the homogeneous medium selfshielding model.

The absorption processes are more involved compared to the Th/U-233 cycle. The fission processes were discusscd above. The $U-235(n, \gamma)$ reaction rate is relatively low. It is moderator independent in the infinitely dilute model and increases, due to high neutron population, in the homogeneous medium self-shielding model. The $U-238(n, y)$ reaction rate, with no fissile material present, should follow the trends shown by $T h(n, \gamma)$ reaction rate. The He and steam cooled blankets indicate such a trend due to relatively low sensitivity of the U-235 fission rate to the resonance self-shielding level. However, in the water cooled blanket case, the increase in neutron source causes the $U-238(n, \gamma)$ reaction rate to increase with self-shielding level. Table 4-4 presents the absorption in the resonance and non-resonance energy ranges as a function of self-shielding leve? for this case. The two competing processes described above emerge clearly from the table. The $\mathrm{ThO}_{2}$-He case is given for comparison. The Pu-239 production rate, as a function of position in the blanket, flattens with higher self-shielding level. 
TABLE 4-4

INTEGRATED Th-232 AND U-238 $(n, \gamma)$ REACTIONS OVER THE RESONANCE AND NON-RESONANCE ENERGY RANGES PER NEUTRON EMITTED FROM PLASNA

\begin{tabular}{|c|c|c|c|c|}
\hline $\begin{array}{l}\text { BLANKET } \\
\text { COMBINATION }\end{array}$ & SELF-SHIELDING & $\begin{array}{l}\text { INF INITELY } \\
\text { DILUTE }\end{array}$ & $\begin{array}{l}\text { HOMOGENEOUS } \\
\text { MEDIUM }\end{array}$ & $\begin{array}{l}\text { HETEROGENEOUS } \\
\text { MEDIUM }\end{array}$ \\
\hline \multirow{4}{*}{$\begin{array}{l}\mathrm{UO}_{2}- \\
- \text { WATER } \\
(0.25 \% \text { U-235 } \\
\text { TAILS) }\end{array}$} & $14 \mathrm{MeV}-5.5 \mathrm{keV}$ & 0.198 & 0.271 & 0.278 \\
\hline & $5.5 \mathrm{keV}-0.68 \mathrm{eV}$ & 1.770 & 1.290 & 1.253 \\
\hline & $<0.68 \mathrm{eV}$ & 0.071 & 0.683 & 0.737 \\
\hline & TOTAL & 2.039 & 2.244 & 2.268 \\
\hline \multirow{4}{*}{$\begin{array}{l}\mathrm{ThO}_{2}- \\
-\mathrm{He}\end{array}$} & $14 \mathrm{MeV}-5.5 \mathrm{keV}$ & 0.956 & 0.935 & 0.940 \\
\hline & $5.5 \mathrm{keV}-0.68 \mathrm{eV}$ & 0.366 & 0.336 & 0.330 \\
\hline & $<0.68 \mathrm{eV}$ & 0.025 & 0.034 & 0.032 \\
\hline & TOTAL & 1.347 & 1.305 & 1.302 \\
\hline
\end{tabular}


The net fissile material production, showing the same trends as in the Th/U-233 cycle, decreases with increasing self-shielding level. The multiplication factor follows the same pattern as the total source due to the common dependence on the fissions of U-235 and U-238. The leakage from the blanket to the reflector follows the pattern described in the Th/U-233 cycle. The net fissile production, multiplication factor and blanket right leakage, as a whole, are more pronounced, relative to the $\mathrm{Th} / \mathrm{U}-233$ cycle, due to the presence of $\mathrm{U}-235$.

The main resonance self-shielding effects, as in the Th/U-233 cycle discussion, are due to finite dilution of the resonance absorber (U-238). The spacial effects are relatively small and are actually obscured in the steam and $\mathrm{He}$ cooled blanket cases. However, in the water cooled blanket, the spacial effects are not negligible (although smali). This suggests that spacial resonance selfshielding effects can be increasingly important when using good moderator (water) and higher fissile material content. This will be the subject of the next section. 


\subsection{ENRICHED FUEL BLANKET}

Following the previous section results, specifically the pure spacial self-shielding effects in the $\mathrm{UO}_{2}$-water blanket combination, this section is devoted to the analysis of the $\mathrm{UO}_{2}$-water case, where the U-235 content in Uranium is varied. The variation in U-235 fraction, while not representing a realistic breeding process, provides a simple tool for examining the self-shielding effects in a breeding blanket (with varied fissile material content). The set-up data presented in Tables 2-1 and 2-2 were used in this set of calculations. The $\mathrm{UO}_{2}$ components number densities for the different $U-235$ fraction are given in Table 2-3. Summary of blanket performance and neutron balance, for the various resonances self-shielding treatments and U-235 fraction, is presented in Table $5-1$.

The primary source, the fusion neutron, is normalized to one. The secondary source is composed of resonance self-shielding independent fast sources $((n, 2 n)$ and $(n, 3 n)$ processes $)$ and resonance self-shielding dependent intermediate and thermal sources (fission). The total source increases with U-235 fraction and sclf-shielding level, as a result of the increase in U-235 fission reaction rate. The U-238 fission and, to a smaller extent, the $U-238(n, 3 n)$ reaction, follow the same pattern. All absorption processes exhibit the same trends discussed above, due to their direct dependence on total neutron population.

Two general blanket performance features deserve detailed analyses. The multiplication factor, which follows the fission processes pattern, is plotted in Figure 5-1 as a function of the U-235 fraction for the various self-shielding treatments. The starting point $(0.25 \% \mathrm{U}-235$ in Uranium, discussed previousiy in Section 4) shows an increase of about $100 \%$ in the multiplication factor due to inclusion of finite dilution self-shielding effects and about $3 \%$ increase due to the pure spacial effects. As the U-235 content increases, both the finite dilution and the spatial effects are more pronounced (e.g. for $1 \%$ U-235 in Uranium the multiplication factor increases respectively by about $400 \%$ and $12 \%$ ). The net fissile material production ( $\mathrm{Pu}-239$ production minus U-235 destruction), as function of the U-235 fraction, for the various self-shielding 
TABLE 5-1

O/PU-239 CYCLE: BLANKET PERFORMANCE AND NEUTRON BALANCE PER NEUTROH

EMITTED FROM PLASHA FOR VARIOUS SELF-SHIELDING TREATMENTS ANO U-235 FRACTIONS ( ${ }_{2}$ O MODERATION)

\begin{tabular}{|c|c|c|c|c|c|c|c|c|c|c|c|c|}
\hline \multirow{2}{*}{$\begin{array}{c}\text { U-235 ENRICHMENT } \\
\text { RESOHANCE } \\
\text { SELF-SHIELDING } \\
\text { TREATMENT }\end{array}$} & \multicolumn{3}{|c|}{0.258} & \multicolumn{3}{|c|}{$1.00 \%$} & \multicolumn{3}{|c|}{1.758} & \multicolumn{3}{|c|}{$2.5 x$} \\
\hline & $\begin{array}{c}\text { INFINITELY } \\
\text { DILUTE }\end{array}$ & $\begin{array}{c}\text { HOMO- } \\
\text { GENEOUS } \\
\text { MEDIUN }\end{array}$ & $\begin{array}{l}\text { HETERO- } \\
\text { GENEOUS } \\
\text { MEDIUM }\end{array}$ & INFINITELY & $\begin{array}{l}\text { HOMO- } \\
\text { GENEOUS } \\
\text { MEOIUH }\end{array}$ & $\begin{array}{l}\text { HETERO- } \\
\text { GENEOUS } \\
\text { MEDIUH }\end{array}$ & $\begin{array}{c}\text { INFINITELY } \\
\text { DILUTE }\end{array}$ & $\begin{array}{l}\text { HOMO- } \\
\text { GENEOUS } \\
\text { MEDIUH }\end{array}$ & $\begin{array}{l}\text { HETERO- } \\
\text { GENEOUS } \\
\text { MEUIUH } \\
\end{array}$ & $\begin{array}{c}\text { INFIHITELY } \\
\text { DILUTE }\end{array}$ & $\begin{array}{l}\text { HOMO- } \\
\text { GENEOUS } \\
\text { MEDIUM }\end{array}$ & $\begin{array}{l}\text { HE TERO- } \\
\text { GENEOUS } \\
\text { MEDIUM }\end{array}$ \\
\hline SOURCES: & & & & & & & & & & & & \\
\hline PLASMA . & 1.000 & 1.000 & 1.000 & 1.000 & 1.000 & 1.000 & 1.000 & 1.000 & 1.000 & 1.000 & 1.000 & 1.000 \\
\hline$U-235 \overline{v\left[r^{4}\right.}$ & 0.123 & 0.964 & 1.041 & 0.339 & 4.403 & 5.041 & 0.502 & 9.432 & 11.746 & 0.656 & 18.586 & 26.855 \\
\hline$U-238(n, 2 n)$ & 0.145 & 0.147 & 0.147 & 0.144 & 0.153 & 0.156 & 0.144 & 0.163 & 0.168 & 0.143 & .0 .181 & 0.199 \\
\hline$U-238(n, 3 n)$ & 0.136 & 0.136 & 0.136 & 0.135 & 0.135 & 0.135 & 0.134 & 0.134 & 0.134 & 0.133 & 0.133 & 0.133 \\
\hline$U-238 \overline{V_{f} \phi}$ & 1.081 & 1.209 & 1.221 & 1.104 & 1.713 & 1.806 & 1.119 & 2.437 & 2.777 & 1.133 & 3.748 & 4.932 \\
\hline SS-316 $(n, 2 n)$ & 0.035 & 0.035 & 0.035 & 0.035 & 0.035 & 0.035 & 0.035 & 0.035 & 0.035 & 0.035 & 0.035 & 0.035 \\
\hline $\operatorname{Zr} \quad(n, 2 n)$ & 0.093 & 0.093 & 0.093 & 0.093 & 0.093 & 0.094 & 0.093 & 0.094 & 0.095 & 0.093 & 0.095 & 0.097 \\
\hline TOTAL SOURCES & 2.613 & 3.584 & 3.673 & 2.850 & 7.532 & 8.267 & 3.027 & 13.295 & 15.955 & 3.193 & 23.778 & 33.251 \\
\hline SINKS: & & & & & & & & & & & & \\
\hline$\overline{U-235}(n, \gamma)$ & 0.011 & 0.082 & 0.088 & 0.034 & 0.422 & 0.482 & 0.055 & 0.993 & 1.236 & 0.075 & 2.110 & 3.047 \\
\hline U-235 FISSION & 0.050 & 0.398 & 0.430 & 0.137 & 1.816 & 2.080 & 0.202 & 3.890 & 4.845 & 0.263 & 7.663 & 11.076 \\
\hline $11-238 \quad(n, r)$ & 2.039 & 2.244 & 2.268 & 2.154 & 3.917 & 4.180 & 2.234 & 6.233 & 7.225 & 2.306 & 10.330 & 13.893 \\
\hline U-238 FISSION & 0.288 & 0.344 & 0.338 & 0.297 & 0.517 & 0.551 & 0.303 & 0.780 & 0.903 & 0.309 & 1.255 & 1.689 \\
\hline $\begin{array}{l}\text { ABSORPIION IN } \\
\text { OTIIER MATERIALS }\end{array}$ & 0.225 & 0.516 & 0.549 & 0.228 & 0.860 & 0.974 & 0.233 & 1.399 & 1.746 & 0.240 & 2.420 & 3.546 \\
\hline $\begin{array}{l}\text { SHIELD RIGHI } \\
\text { LEAKAGE }\end{array}$ & $1 \cdot 0^{-5}$ & $1 \cdot 10^{-5}$ & $1 \cdot 10^{-5}$ & $1 \cdot 10^{-5}$ & $2 \cdot 10^{-5}$ & $2 \cdot 10^{-5}$ & $1 \cdot 10^{-5}$ & $3 \cdot 10^{-5}$ & $3 \cdot 10^{-5}$ & $-1 \cdot 10^{-5}$ & $4 \cdot 10^{-5}$ & $5 \cdot 10^{-5}$ \\
\hline TOIAL SINKS & 2.613 & 3.584 & 3.673 & 2.850 & 1.532 & -8.262 & 3.027 & 11.295 & 15.955 & 3.193 & 23.778 & 33.251 \\
\hline $\begin{array}{l}\text { BLAIKET-RIGHT } \\
\text { LFAKAGE }\end{array}$ & 0.057 & 0.140 & 0.141 & 0.065 & 0.389 & 0.438 & 0.071 & 0.792 & 0.988 & 0.076 & 1.557 & 2.280 \\
\hline $\begin{array}{l}\text { MUL IIPL ICATIOH } \\
\text { FACTOR }\end{array}$ & 5.794 & 11.525 & 11.894 & 7.156 & 34.092 & 38.319 & 8.163 & 67.241 & 82.532 & 9.113 & 127.496 & 82.064 \\
\hline $\begin{array}{l}\text { HET FISSILE } \\
\text { ISIERIAL PRCDLCTIDI: }\end{array}$ & 1.978 & 1.754 & 1.750 & 1.983 & 1.679 & 1.618 & 1.977 & 1.350 & 1.144 & 1.970 & 0.557 & -0.230 \\
\hline
\end{tabular}




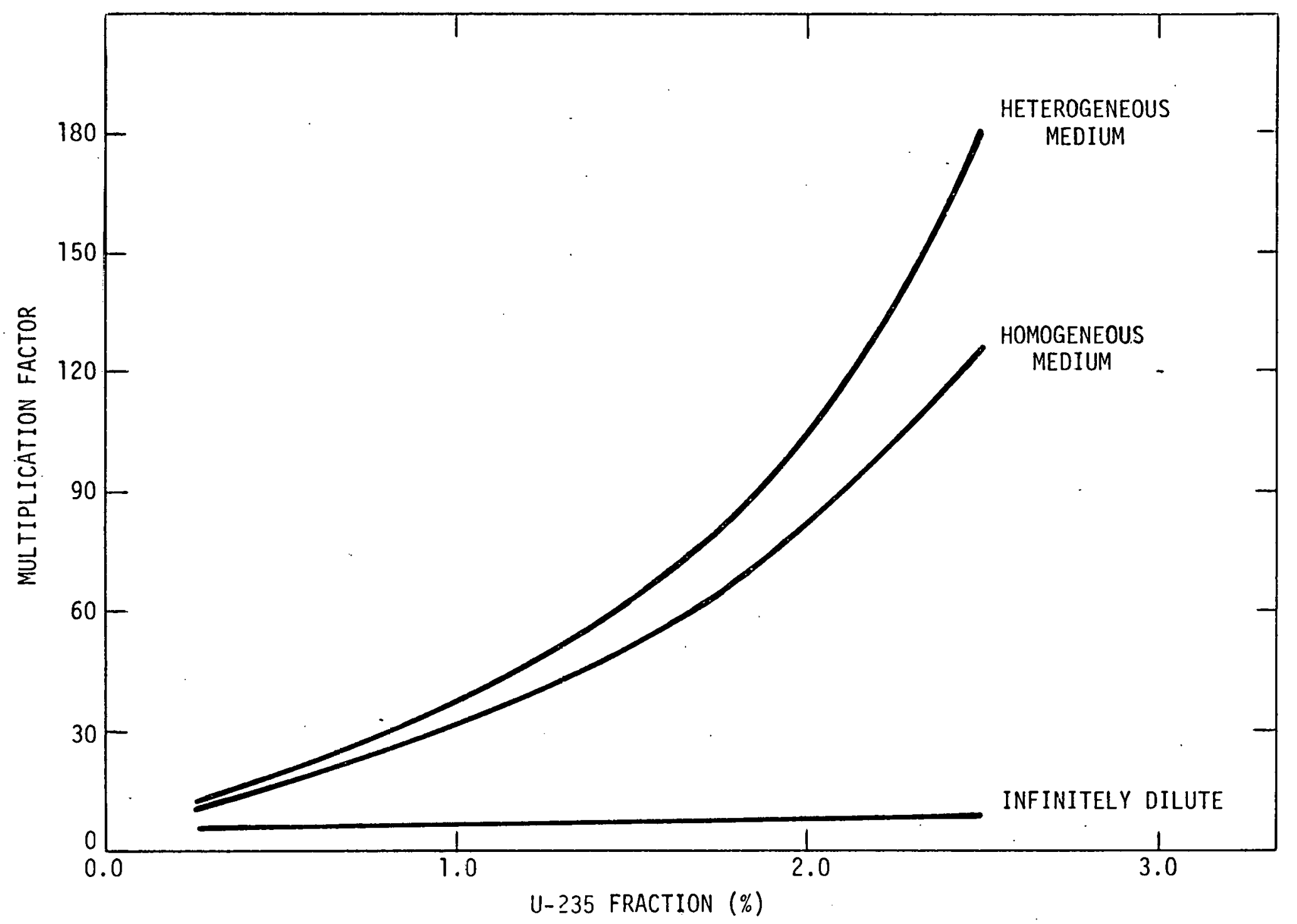

FIG'JRE 5-1. MULTIPLICATIOH FACTOR, IN THE U/PU-239 CYCLE, VERSIS U-235 FPACTION IN URANIUM FOR VARIOUS SELF-SHIELDING TREATMENTS 
treatments is shown in Figure 5-2. The net fissile production in the infinite dilute model is insensitive to the $U-235$ presence, and it's value is twice the primary source. The inclusion of self-shielding effects cause the net production rate to decrease appreciably compared to the infinite dilute model results. The pure spacial effects are increasingly important as the U-235 content increases. The net fissile production, in general, seems to reach a steady state (zero production rate), and the spacial effects are most important in the vicinity of this limit. The leakage from the blanket to the reflector zone, presented in Table 5-1, reflects again the resonance self-shielding level and U-235 content dependence of the neutron population.

Although only water cooled blankets have been analyzed throughout this section, the other moderation possibilities deserve a short discussion. From the results of Section 4, specifically the decreasing differences in resonance integral between values corresponding to different resonance selfshielding treatments, with decreasing moderation properties for a given fuel (see Table 4-3), and the small effect on the blanket performance due to pure spacial resonance self-shielding for poor moderated blanket, it can be concluded that the pure spacial effects and moderator properties (varying only the moderator properties) increase or decrease together. Note the two limiting cases: If the moderator total cross-section is large, there are no fuel lump tio fuel lump interactions and the spacial self-shielding is maximized. If the moderator total cross-section vanishes (assume for the moment only moderator and fuel are present, there are no spacial effects and the homogeneous medium treatment is identical to the heterogeneous medium treatment. The results in section 4 are confined within those two limits. 


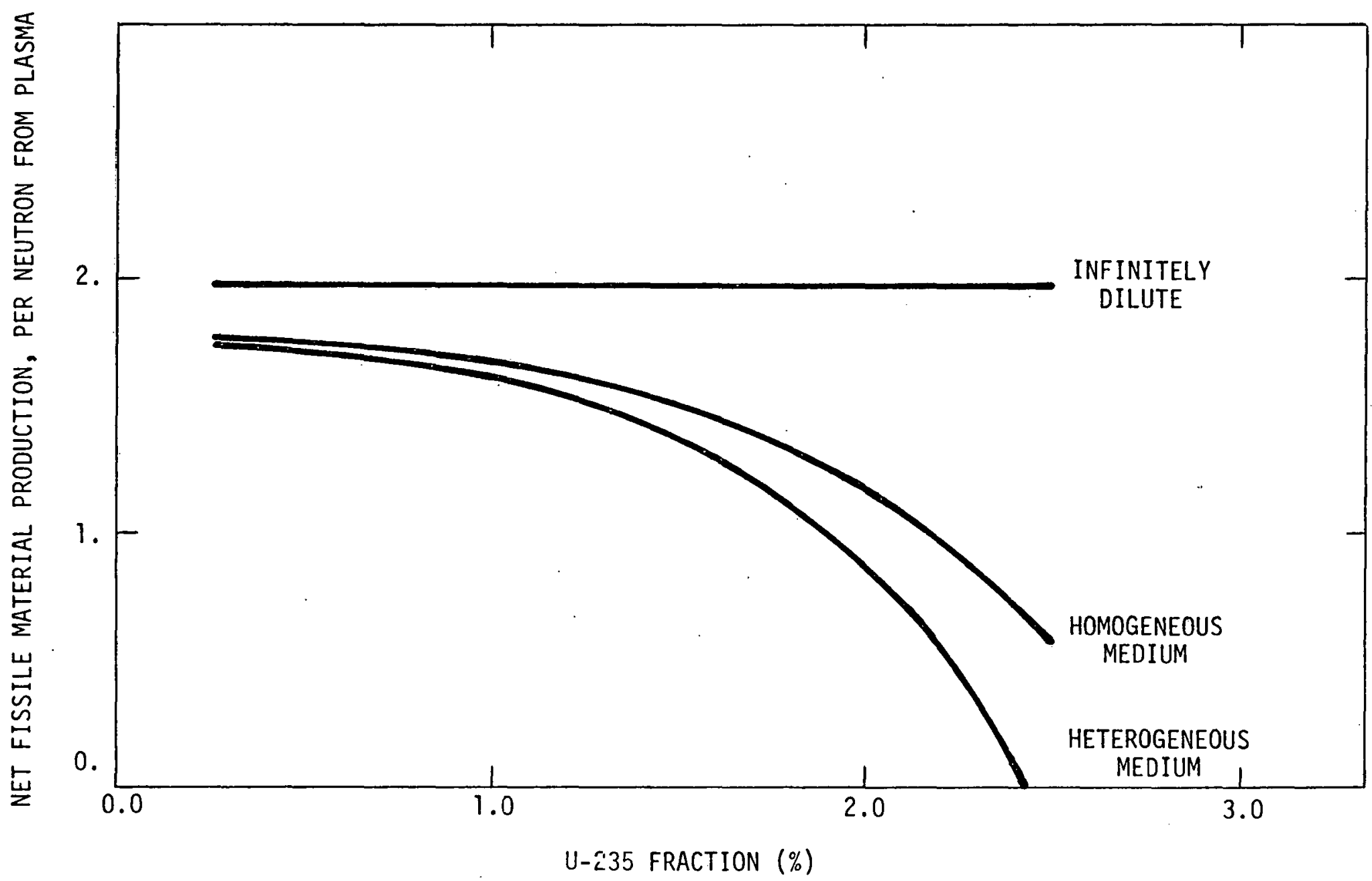

FIGURE 5-2. NET FISSILE MATERIAL PPORUCTION, IN THE U/PU-239 CYCLE, VERSUS U-235 FRACTION IN URANIUM FOR VARIOUS SELF-SHIELDING TREATMENTS 


\subsection{SUMMARY AND CONCLUSIONS}

Two sets of calculations have been analyzed throughout this paper. In the first, a fresh fuel blanket, corresponding to BOL, has been considered. $\mathrm{ThO}_{2}$ and depleted $\mathrm{UO}_{2}$ fuels and water, steam and He coolants were used to form a variety of blanket combinations, which were analyzed using different resonance self-shielding treatments. In the second set of calculations, an enriched $\mathrm{UO}_{2}$ water cooled blanket, corresponding to different stages of blanket fissile material content, was analyzed using the different resonance self-shielding treatment. For both sets of calculations a detailed comparison has been presented regarding the different blanket combinations, and more important, the effects due to the inclusion of different resonance self-shielding levels.

In the present statusi of the computational methods, computer codes and nuclear data, there is no existing estimate for a calculation error upper limit. ${ }^{6}$ Therefore, smal1 (few per-cent) differences in blanket performance, between results corresponding to different resonance self-shielding treatrients, can be neglected. In view of this observation and the calculation results, the following general conclusions can be made:

1. The infinitely dilut: model, which neglects completely the resonance self-shieldinc phenomena, can be used to produce preliminary crude estimates for BOL onity. This model is completely Inadequate when dealing with irradiated breeding blankets.

2. The homogeneous medium self-shielding model, which takes into account the resonance absorber finite dilution, is adequate for BOL, poor moderated blankets and well moderated blankets with low fissile material content situations.

3. The heterogeneous medium self-shielding model, which takes into account lattice spacial details as well as the resonance absorber finite dilution, should be used in high fissile content, well moderated blanket situations. 
The present and future fusion-fission hybrid reactor design efforts will be oriented, necessarily, towards commercial power and/or fissile materialproducing device. The fissile material variations during the blanket life time, the different possible moderation techniques and the necessity for improved accuracy in the hybrid design, suggest that the above conclusions can serve as general guidelines for the generation process of effective energy group cross sections for the hybrid reactor neutronic calculations. 


\subsection{REFERENCES}

1. "Demonstration Tokamak Hybrid Reactor (DTHR) Feasibility Study", Quarterly Progress Report for January 1978 - March 1978, WFPS-TME-086.

2. W. W. Engle, Jr., "A User's Manual for ANISN", Oak Ridge Gaseous Diffusion Plant Report, K-1693 (1967).

3. R. W. Roussin, et al., "The CTR Processed Multigroup Cross Section Library for Neutronics Studies", ORNL/RSIC-37, Oak Ridge National Laboratory (1977).

4. I. I. Bondarenko, "Group Constants for Nuclear Reactor Calculations", Consultants Bureau, New York, (1964).

5. J. R. Lamarsh, "Introduction to Nuclear Reactor Theory", Addison-Wesley Publishing Company, Reading, Massachusetts (1966).

6. R. C. Haight et al., "Reaction Rates in a Uranium Pile Surrounding a 14-MeV Neutron Source: Calculations of the lieale Experiment", Nuclear Science \& Engineering 61, 53 (1976). 
$m_{y}$

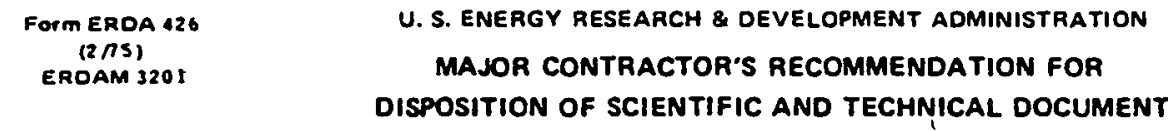

- See Instructions on Roversa

1. EROA ReDort No:

WFPS:TME-79-016

2. Subject Category No:

UC $-20,20 \mathrm{~d}$

3. Title

Resonance Self-Shielding in the Blanket of a Hybrid Reactor

4. Tyou of Oocument (" $\mathrm{x}$ " one)

8. Scientific and Tochnical Report

$\square$ b. Conference poper:

Title of conterance

Date of confer ence

Exact location of conference

c Other (Specify. Theste. Translation. etc.)

5. Copies Trammitted (" $\times$ " one or more)

d. Copies being Iransmitted for standard distribution by EROA-TIC.

$\square$ o. Copies being transrifted for special distribution por attached complete address list."

C. Two completely legible, reproducible copies being transmitted to EROA-TIC.

6. Rocommended Distribution ("' $X$ "' ono)

伐 s. Nor mal handing (after Patent clearance): no restrsints on distributionexceot as may be reauired by the security classification.

$\square$ b. Make available only to U.S. Government agencies and their contractors.

c. Make ovailable onty within EROA and to ERDA contractors

d. Make available only within EROA.

e. Make available only to those listed in item 12 betow.

f. Other (Specify)*

7. Recommended Announcement (" $x$ " one)

Q] 2. Normal procedure may on tollowed."

$\square$ D. Recommono following announcoment limitations:

8. Resson for Restrictions Recommended in 6 of 7 dbove.

[1] aretiminary information.

$\square$ b. Predared primurily for internal use.

$\square$ c. other (Exploin)

9. Patent Clearance (" $X$ " ono)

4]. EROA potant clesranco has peen granted by responsibit ERDA patent groua

$\square$ b. Document has been sant to responsible ERDA pasent groud for clear ance.

10. National security information (For elasajfied document only: " $\boldsymbol{X}$ " one)

$\square$ a. Document does contain nationsl security information other inan restricted data.

$\square$ b. Document does hot contain national security informatisn other than reatricted dato.

11. Copy Reprocuction and Oistribution 21

d. Totel number of copies reprosuced

27

b. Number of copies distributed outsige ortginating organization 5

12. Aaditlonal Intormation or Remarks (Continue on esparate theet, if necesary)

13. Submitted by (Name and Position) (Pleare print or type)"

T. C. Varljen, Manager, Engineering

14. Oraphesation

15: signature $5 / 13 / 79$

